Review article

\title{
Current advances in drug discovery for Chagas disease
}

\section{Cauê Benito Scarim a, *, 1 , Daniela Hartmann Jornada a , Rafael Consolin Chelucci a, Leticia de Almeida ${ }^{\mathrm{b}}$, Jean Leandro dos Santos ${ }^{\mathrm{a}}$, Chung Man Chin ${ }^{\mathrm{a}}$}

a Departamento de Fármacos e Medicamentos, Faculdade de Ciências Farmacêuticas, Universidade Estadual Paulista “Júlio de Mesquita Filho", UNESP, Araraquara, SP, Brazil

b Departamento de Biologia Celular e Molecular, Faculdade de Medicina de Ribeirão Preto, Universidade de São Paulo, USP, Brazil

\section{A R T I C L E I N F O}

\section{Article history:}

Received 26 February 2018

Received in revised form

14 June 2018

Accepted 15 June 2018

Available online 20 June 2018

\section{Keywords:}

Chagas disease

T. cruzi

New compounds

New drugs

\begin{abstract}
A B S T R A C T
Chagas disease, also known as American trypanosomiasis, is one of the 17 neglected tropical diseases (NTDs) according to World Health Organization. It is estimated that 8-10 million people are infected worldwide, mainly in Latin America. Chagas disease is caused by the parasite Trypanosoma cruzi and is characterized by two phases: acute and chronic. The current therapy for Chagas disease is limited to drugs such as nifurtimox and benznidazole, which are effective in treating only the acute phase of the disease. In addition, several side effects ranging from hypersensitivity to bone marrow depression and peripheral polyneuropathy have been associated with these drugs. Therefore, the current challenge is to find new effective and safe drugs against this NTD. The aim of this review is to describe the advances in the medicinal chemistry of new anti-chagasic compounds reported in the literature in the last five years. We report promising prototypes for drug discovery identified through target-based and phenotypebased strategies and present some important targets for the development of new synthetic compounds.
\end{abstract}

(C) 2018 Elsevier Masson SAS. All rights reserved.

\section{Contents}

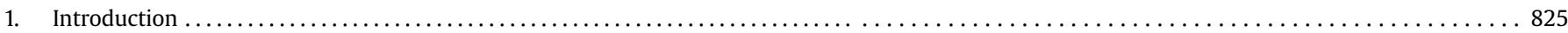

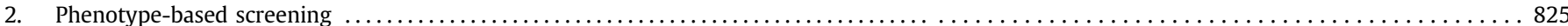

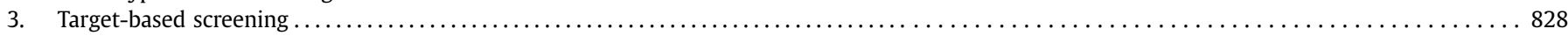

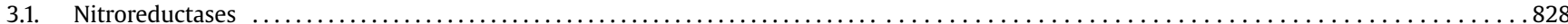

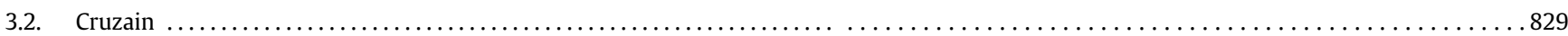

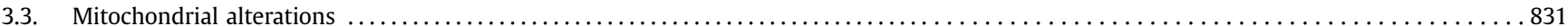

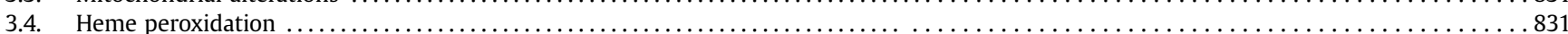

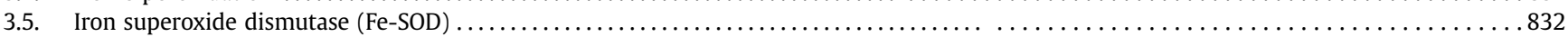

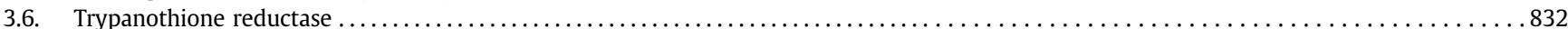

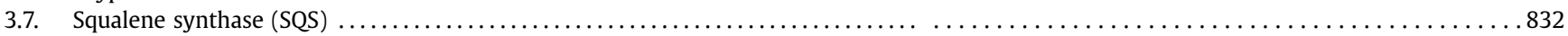

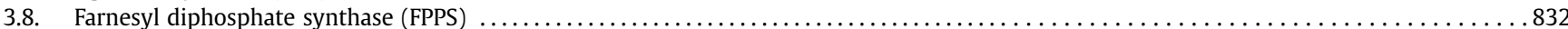

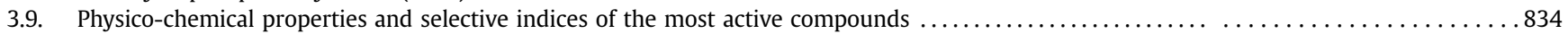

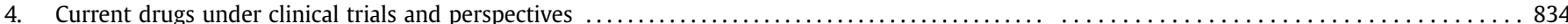

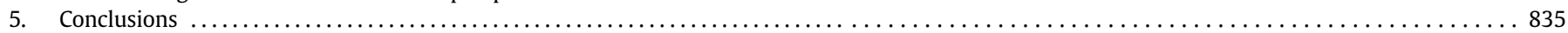

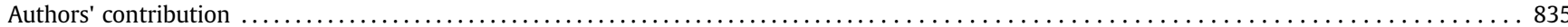

\footnotetext{
Abbreviations: NTD, neglected tropical disease; T. cruzi, Trypanosoma cruzi; TDD, target-based drug discovery; PDD, phenotypic-based drug discover; NFX, nifurtimox; BZN, benznidazole; SI, selective index; $\mathrm{CC}_{50}$, concentration to inhibit grow of $50 \%$ control/human cells; $\mathrm{IC}_{50}$, concentration to inhibit grow of $50 \%$ of $T$. cruzi; $\mathrm{MDR}$-TB, Multidrug-resistant-Mycobacterium tuberculosis; TcTIM, glycolytic enzyme triosephosphate isomerase; NTRs, Nitroreductases; FMN, flavin mononucleotide; FAD, flavin adenine dinucleotide; ATPs, adenosine triphosphate synthesis; SOD, Superoxide dismutase; ${ }^{1} \mathrm{H}$ NMR, ${ }^{1} \mathrm{H}$ - Magnetic Nuclear Resonance; Fe-SOD, Iron superoxide dismutase; TR, Trypanothione reductase; SQS, enzyme squalene synthase; FPPS, Farnesyl Diphosphate Synthase; TcTIM, glycolytic enzyme triosephosphate isomerase; FPP, farnesylpyrophosphate; USP, University of São Paulo.

* Corresponding author.

E-mail address: cauebenitos@gmail.com (C.B. Scarim).

1 Present address: Rodovia Araraquara-Jaú km-1 s/n, campus ville, 14800-903, Araraquara - SP, Brazil.
} 


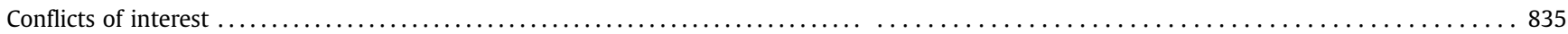

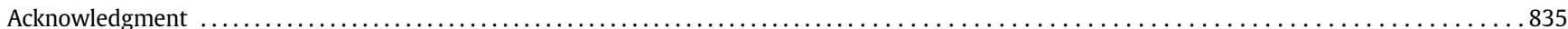

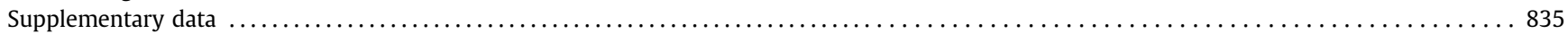

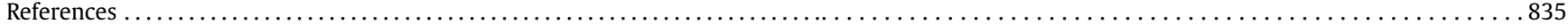

\section{Introduction}

Chagas disease, also known as American trypanosomiasis, is one of the 17 neglected tropical diseases (NTDs) listed by WHO. NTDs prevail in tropical and subtropical countries and since they usually affect people with lower socio-economic status, they are not a profitable venture for the pharmaceutical industry [1-4]. The disease was discovered 109 years ago by the Brazilian sanitary physician Carlos Chagas, and is caused by parasite Trypanosoma cruzi (T. cruzi), a hemoflagellate protozoan of the order Kinetoplastida and family Trypanosomatidae $[1,5,6]$.

Clinically, Chagas disease has two phases: an acute early stage (acute phase) lasting a few weeks which is characterized by fever and many circulating parasites in bloodstream, and the chronic phase which can be classified into the indeterminate and determinate forms. The indeterminate form is characterized by a febrile state and few parasites in the bloodstream, and the determinate form manifests with significant cardiac (chagasic cardiopathy), digestive (megacolon and megaesophagus) and neurological changes $[7,8]$.

Chagas disease is endemic in 21 Latin American countries. Due to globalization, this parasite has spread across European countries like Austria, Belgium, France, Germany, Italy, Netherlands, Portugal, Spain, Sweden, Switzerland and the United Kingdom, as well as Australia, Japan, Canada and the southern United States bordering with Mexico [9,10]. The World Health Organization (WHO) estimates that 8 million people are infected with T. cruzi and more than 10,000 die every year on account of the infection [11]. Furthermore, an increase in the number of HIV-positive patients and indiscriminate use of corticosteroids, has led to the reactivation of asymptomatic Chagas disease indicating that $T$. cruzi is also an opportunist parasite [12,13].

Current chemotherapy for Chagas disease is restricted to only two nitroheterocyclic drugs: nifurtimox (NFX) (1) and benznidazole (BZN) (2) (Fig. 1), discovered in the 1960s and 70s, respectively $[14,15]$. The likely mechanism of action of both drugs is the formation and accumulation of free radicals from the nitro groups which overwhelm the antioxidant capabilities of $T$. cruzi and eventually kill the parasite [16]. NFZ and BZN are more effective in the acute phase and the treatment response varies according to the strains of T. cruzi. Both drugs show limited activity in the indeterminate form of chronic phase. In addition, NFX and BZN show several side effects such as anorexia, psychic alterations, digestive manifestations, bone marrow depression, peripheral polyneuropathy, hypersensitivity, lymphadenopathy, thrombocytopenic purpura, and agranulocytosis [17-26].

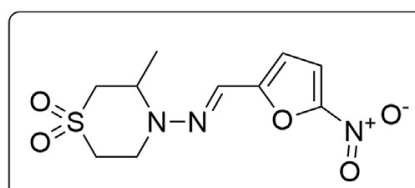

(1) nifurtimox (NFX)

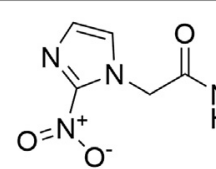<smiles>NCc1ccccc1</smiles>

(2) benznidazole (BZN)
Fig. 1. NFX and BZN structures. Standard drugs against Chagas disease.
Drug discovery for NTDs has been suffering from the lack of interest by pharmaceutical companies due to low income of the majority of the affected people. Chagas disease remains a major challenge and all current drug discovery programs are aimed at identifying drugs or vaccines to eliminate T. cruzi from the host [27]. In drug development, two different approaches are typically undertaken to identify compounds of interest within a specific program: target-based drug discovery (TDD) or phenotype-based drug discovery (PDD) [28].

In the past three decades, TDD has been a dominant approach in identifying new drugs for inadequately treated medical concerns $[29,30]$. However, the interest in PDD approaches has been revived in recent years. PDD involves evaluating different chemicals against the pathogen's phenotype in a biological system such as an animal model or a cell line [30]. In this review, we have discussed the different drug discovery approaches used for Chagas disease, as well as some drug targets explored in the last few years. In this context, we have presented the current advances in the medicinal chemistry of new antichagasic compounds reported in the literature in the last five years. We have focused on the most active analogs with selective index (SI) superior or equal to 10 that have been reported in studies obtained from the PubMed, Web of Science, and Scopus databases. The SI values were calculated as a ratio of the $\mathrm{CC}_{50}$ (concentration to inhibit the growth of $50 \%$ control/ human cells) and $\mathrm{IC}_{50}$ (concentration to inhibit the growth of $50 \%$ of T. cruzi) to compare the molecules and discuss the development of novel antichagasic lead compounds.

\section{Phenotype-based screening}

Phenotypic screens have the advantage of the whole organism and, therefore, all the targets and biological pathways of the organism are exposed to the compound [31]. PDD approaches, thus, do not rely on previous knowledge of a specific drug target or a hypothesis regarding its role in the disease [30]. Some examples of compounds discovered through phenotypic assays against $T$. cruzi are discussed below.

Thiazoles are an important class of compounds that are able to inhibit T. cruzi growth. Alvarez et al. synthesized 82 new thiazoles derivatives and discovered three compounds $(\mathbf{3}, \mathbf{4}$ and $\mathbf{5})$ showing activity against epimastigotes (Tulahuen 2 strain) and amastigotes (Sylvio X-10 strain) (Fig. 2). Their results showed that the $\mathrm{IC}_{90}$ values of analogs 3,4 and 5 against amastigote forms were $1.30 \mu \mathrm{M}$, $0.31 \mu \mathrm{M}$ and $1.4 \mu \mathrm{M}$, respectively. All of them presented an SI above 1000 , about five times higher than NFX. In addition, they did not show any nonspecific toxicity or mutagenic activity. Compounds 4 and 5 were evaluated in $\mathrm{BAL} / \mathrm{c}$ mice during the acute phase of Chagas disease, and both showed toxicity against Trypomastigotes (Y strain). They were able to decrease parasitemia at the doses of 50,100 and $200 \mathrm{mg} / \mathrm{kg} /$ day, with the highest dose showing results similar to that of BZN [32].

The same research group has synthesized a series of new thiazole analogs that are more hydrophilic than compound $\mathbf{4}$. Compound 6 (Fig. 2), the most promising analog, was very active in in vitro assays against the epimastigote (Tulahuen 2 strain), trypomastigote (Y strain) and amastigote forms (Sylvio X-10 strain). At 


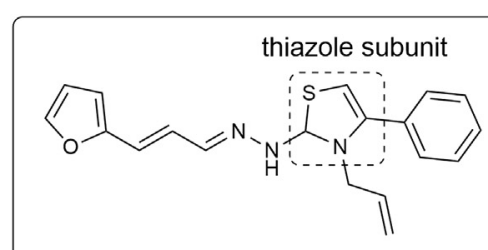

(3)

$\mathrm{IC}_{50}=3.2 \mu \mathrm{M}$ (epimastigote)

$\mathrm{IC}_{50}=<0.24 \mu \mathrm{M}$ (amastigote)

$\mathrm{SI}=>1000$ (amastigote)

Álvarez et al., 2014

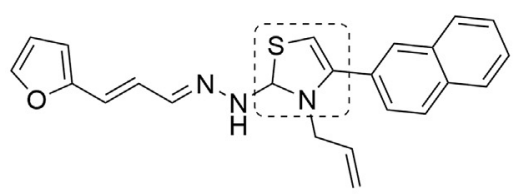

(5)

$\mathrm{IC}_{50}=2.4 \mu \mathrm{M}$ (epimastigote)

$I_{50}=<0.21 \mu \mathrm{M}$ (amastigote)

$\mathrm{SI}=>1000$ (amastigote)

Álvarez et al., 2014

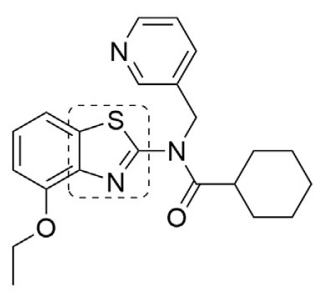

(7)

$\mathrm{IC}_{50}=0.16 \mu \mathrm{M}$ (amastigote)

$\mathrm{SI}=>200$ (amastigote)

Kaiser et al., 2015

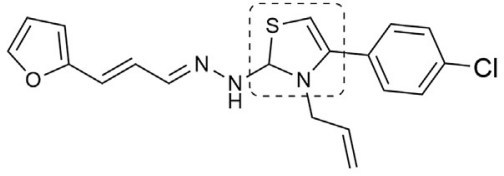

(4)

$\mathrm{IC}_{50}=1.3 \mu \mathrm{M}$ (epimastigote)

$\mathrm{IC}_{50}=<0.25 \mu \mathrm{M}$ (amastigote)

$\mathrm{SI}=>1000$ (amastigote)

Álvarez et al., 2014

INCREASING

HYDROPHYLICITY

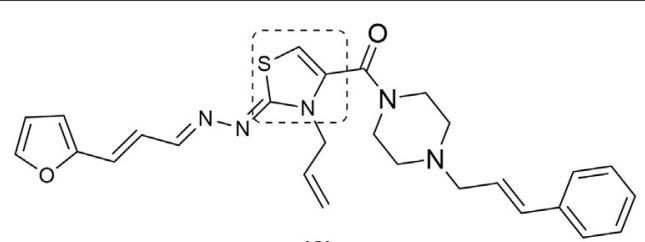

(6)

$\mathrm{IC}_{50}=0.7 \mu \mathrm{M}$ (amastigote)

$\mathrm{SI}=433$ (amastigote)

Álvarez et al., 2015

Fig. 2. Thiazoles analogs structures. Novel thiazole derivatives actives against $T$. cruzi strains.

$0.7 \mu \mathrm{M}$, it reduced $50 \%$ of $T$. cruzi amastigotes and showed SI of 433 . Compound 6 also suppressed the parasitemia in mice and was stable under hydrolysis in rat microsomal hepatocytes. In addition, compound $\mathbf{6}$ was not mutagenic in vitro, non-clastogenic in vivo and exhibited low acute toxicity in the mice. Although it was not more active than BZN in the animal model of acute disease when administered along with a vehicle (oil microemulsion), compound 6 reduced parasitemia, mortality, and anti-T. cruzi IgG antibody levels [33].

Other active prototypes containing thiazole subunit have been discovered through the 'repurposing strategy', which aims to discover novel activities for already described drugs [34]. In this case, the researchers performed a repurposing screening in Malaria Box. They started with 400 compounds and then selected 21 of the most active compounds against amastigotes of $T$. cruzi (Tulahuen CL2 strain) with IC $\mathrm{C}_{50}$ values lower than $5.0 \mu \mathrm{M}$ and SI superior to 10 . On the basis of Lipinski's rule of five- cluster analysis, the absence of toxicophores, novelty and frequent hitters, drug-likeness and number of hits for cluster- compound 7 (Fig. 2) was identified. However, in spite of its high $\mathrm{IC}_{90}$, this compound had suboptimal plasma drug concentration and therefore was not considered for further development [35].

Imidazothiazole derivatives were also synthesized and assayed against $T$. cruzi strains. Their $\mathrm{IC}_{50}$ values ranged between 0.045 and $52 \mu \mathrm{M}$. The best compounds, $8\left(\mathrm{IC}_{50}=0.04 \mu \mathrm{M} / \mathrm{SI}=1600\right) \mathbf{9}$ $\left(\mathrm{IC}_{50}=0.035 \mu \mathrm{M} / \mathrm{SI}=1828\right)$ and $\mathbf{1 0}$ (Fig. 3), also showed high SI values ranging from 1828 to 1663 . Compound 10, a bio-isostere of delamanid (11), was the most promising analog [36].

BZN derivatives have been developed in order to optimize the antichagasic effect of this drug. With this aim, new 1, 2, 3-triazole analogs were synthesized and evaluated, and three promising compounds of this series showed better activity against the $T$. cruzi Tulahuen strain compared to the reference drug. The best compound was $N$-benzyl-2-[4-(4-nitrophenyl)-1H-1,2,3-triazol- $1^{1}$-yl] acetamide (12) (Fig. 4), which showed a potent trypanocidal activity $\left(\mathrm{IC}_{50}=7.0 \mu \mathrm{M}\right)$, and was also active against trypomastigotes of $T$. cruzi (Y strain). Compound 12 was capable of crossing the macrophage membrane to exert its effect and showed low cytotoxicity to the host $(\mathrm{SI}=114.3)$. Therefore, this analog was selected for the 'proof of concept' of using T. cruzi trypomastigotes (Y strain) infected mice as the model for Chagas disease. However, compound 12 showed poor water solubility resulting in pharmacokinetic issues [37].

Another study developed a series of 5-nitroindazole derivatives against $T$. cruzi. The researchers obtained 13 compounds that were more selective than BZN, showing SI ranging between 18.10 and 


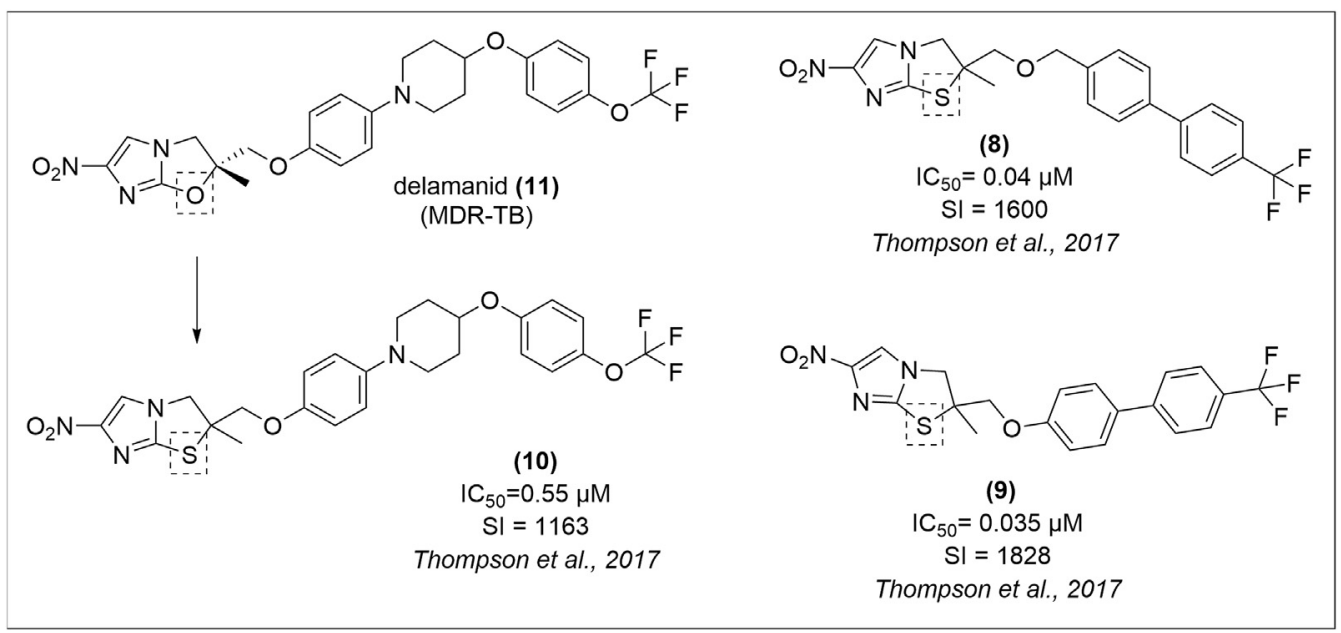

Fig. 3. Structures of imidazothiazoles derivatives. Novel Thiazoles analogs based on delamanid chemical structure.

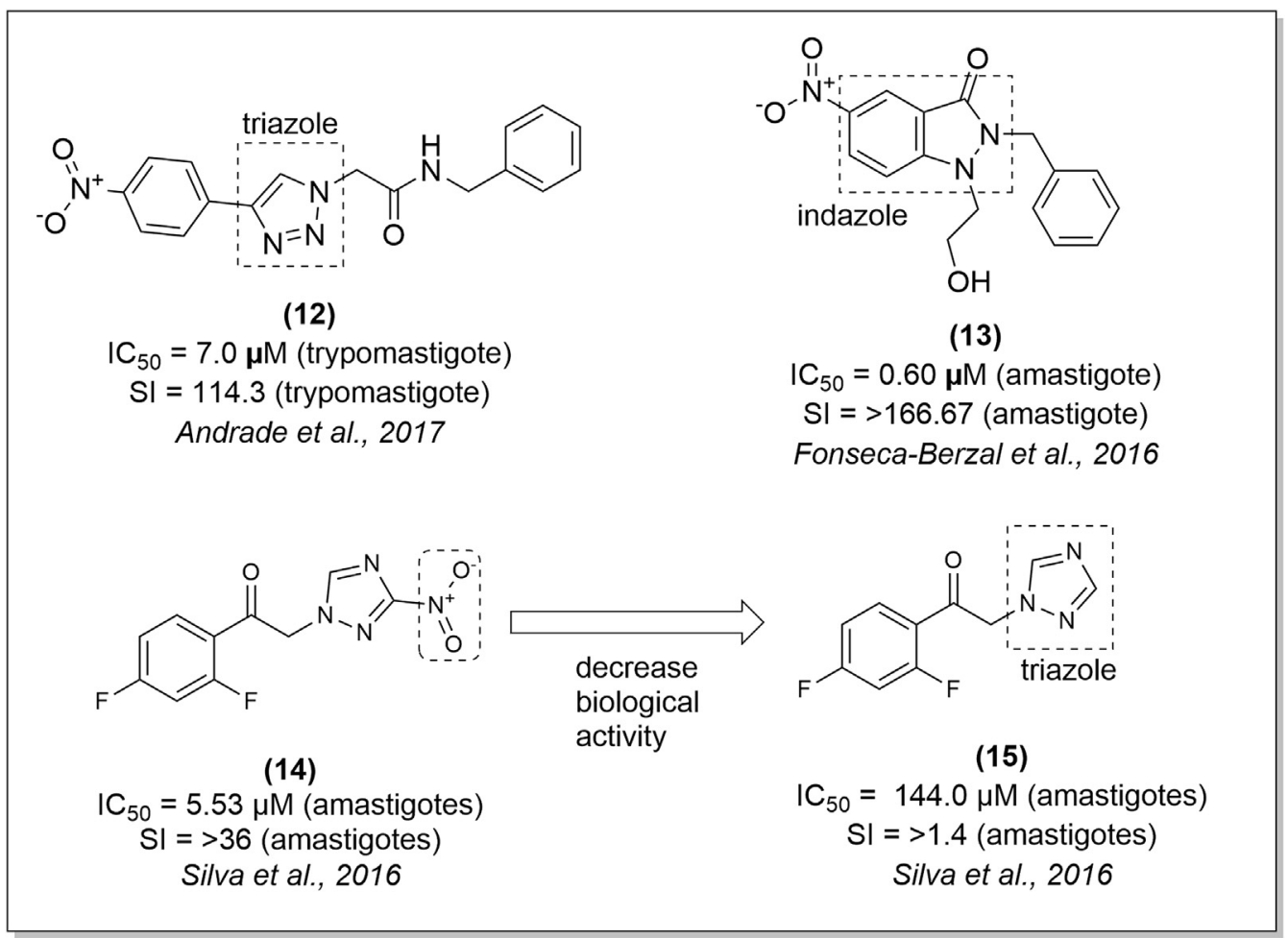

Fig. 4. Structures of triazoles and indazole analogs. The activity of triazoles and indazole derivatives against $T$. cruzi.

162.02 against the epimastigotes. In addition, when tested against amastigotes, four compounds were more selective than BZN. The SI values obtained ranged from 474.07 to 1163.64 . The most active compound against both forms of T. cruzi CL Brener strain (DTU TcVI) was compound $\mathbf{1 3}$ (Fig. 4), which was also very active against T. cruzi $\mathrm{Y}$ strain $\left(\mathrm{IC}_{50}=0.60 \mu \mathrm{M}\right.$ and $\mathrm{SI}=166.67$ against amastigotes forms), with a 3-fold higher selectivity than the reference drug BZN [38].

Bio-isosteric replacement was used to obtain new 1,2,4-triazolic derivatives against $Y$ strain of $T$. cruzi. The most active compound 14 (BZN bio-isosteric) showed an $\mathrm{IC}_{50}$ of $5.53 \mu \mathrm{M}$ and SI values above 36. However, this compound was less efficient than the parental drug. The researchers observed that the presence of a nitro group was extremely relevant and its absence, as observed for compound 15, reduced its anti $T$. cruzi activity by 26 -fold (Fig. 4). Finally, they concluded that the BZN bio-isosterics can be used as parental drugs for the development of new antichagasic drugs [39].

Lapatinib (16) and its derivative NEU-617 (17) are used to treat lung cancer (Fig. 5). Interestingly, these compounds are also active against Trypanosoma brucei, the etiologic agent of Human African trypanosomiasis (HAT). One group screened 66 new derivatives of lapatinib (16) and NEU-617 (17) against the amastigote forms of T. cruzi. The researchers found 32 active compounds that were capable of inhibiting cell proliferation by over $65 \%$. The best analog was a homopiperazinyl sulfonamide-substituted derivative, compound 18 (Fig. 5), that presented an $\mathrm{EC}_{50}=0.51 \mu \mathrm{M}$ and an 
$\mathrm{SI}=85.6$. To expand the screening, the researchers incorporated a molecular modification in the quinazoline scaffold and tested other bicyclic aromatic derivatives. They isolated compound 19 (((3Chloro-4-((3-fluorobenzyl)oxy)phenyl)amino)-6-(4-((4-methyl1,4-diazepan-1-yl)sulfonyl)phenyl)quinoline-3-carbonitrile) (Fig. 5) as a potent analog $\left(\mathrm{IC}_{50}=0.09 \mu \mathrm{M}\right)$, which is approximately 2 -fold more selective than compound $\mathbf{1 8}$. They finally concluded that quinazoline moiety is a promising scaffold to develop novel lead compounds through cross-parasite screening [40].

In another study, the researchers synthesized a series of alphapyrone derivatives and evaluated their efficacy against $T$. cruzi. The two best compounds, 20 and $\mathbf{2 1}$ (Fig. 6), have shown high efficacy against the trypomastigotes forms of $T$. cruzi (Y strain), with $\mathrm{IC}_{50}$ values of 1.3 and $2.6 \mu \mathrm{M}$, respectively. Although the compounds had SI values higher than 70 , both failed to adequately eliminate the intracellular amastigotes of $T$. cruzi (Y strain). Nevertheless, the pyrone derivative $\mathbf{2 1}$ was evaluated in an acute-phase experimental model (BALB/c mice) of Chagas disease and compared to BZN. Five days post-infection, compound $\mathbf{2 1}$ was administered intraperitoneally at $30 \mathrm{mg} / \mathrm{kg} /$ day and parasitemia was followed from the $8^{\text {th }}-14$ th days post infection. The results showed that compound 21 was able to reduce $55 \%$ of the parasite burden [41].

A series of $\mathrm{N}^{1}, \mathrm{~N}^{2}$-dibenzylethane-1,2-diamine hydrochlorides (benzyl diamines) and $\mathrm{N}^{1}$-benzyl, $\mathrm{N}^{2}$-methyferrocenylethane-1,2diamine hydrochlorides (ferrocenyl diamines) were found to be active against epimastigotes of $T$. cruzi (Y strain). Velásques et al. (2014) have shown that the ferrocenyl group linked into benzyl diamines increases its anti-T. cruzi activity. Compound 22 (Fig. 7) ( $\mathrm{IC}_{50}=2.21 \mu \mathrm{M} ; \mathrm{SI}=14.6$ ) was found to be the most potent trypanocidal agent [42].

Through another random screening, one group obtained compound 23 ((E)-5-(4-hydroxyphenyl)-3-[2-oxo-1-(2-oxo-2naphthylethylthio)-2-naphthylethylidene]-3H- [1,2]dithiole), a $3 \mathrm{H}-[1,2]$ dithiole derivative with a highly activity against the epimastigotes form of $T$. cruzi (Tulahuen 2 strain). This compound exhibited $\mathrm{IC}_{50}=4.9 \mu \mathrm{M}$ and $\mathrm{SI}=12.8$, but the mechanistic studies were not able to correlate its activity with TcTIM (glycolytic enzyme triosephosphate isomerase), cruzipain or membrane sterol biosynthesis (Fig. 8) [43].

\section{Target-based screening}

For the target-based approach, the starting point is the identification of putative molecular targets that play important roles in the disease [29]. Small-molecules are then designed to disrupt specific targets that (a) are essential for parasite survival, and (b) are either absent from, or structurally dissimilar to those occurring in the host [28].

Several targets extracted from $T$. cruzi genome data analysis have been investigated for the development of high throughput target-based drug screening assays [44]. These screens notably included enzymes belonging to the ergosterol biosynthesis pathway and several proteases (such as cysteine protease cruzain). Many additional $T$. cruzi putative drug targets including intermediates of pathways of glycolysis (e.g., glucose-6-phosphate dehydrogenase), thiol-dependent redox metabolism (e.g., trypanothione synthetase) and polyisoprenoids biosynthesis, have been identified, validated and used in various drug discovery programs [28].

\subsection{Nitroreductases}

Nitroreductases (NTRs) catalyze the nitroreduction process and are classified into two types on the basis of their oxygen sensitivity [45]. Type I NTRs, a class of flavin mononucleotide-binding proteins commonly found in bacteria, are oxygen-insensitive and function via a series of two-electron reduction of the nitro-group, leading to the formation of DNA damaging moieties [46]. Type II NTRs are ubiquitous oxygen-sensitive proteins that act as flavin mononucleotide (FMN) or flavin adenine dinucleotide (FAD) as cofactors. They catalyze the one-electron reduction of a substrate, forming a nitro anion radical. In the presence of oxygen, this radical

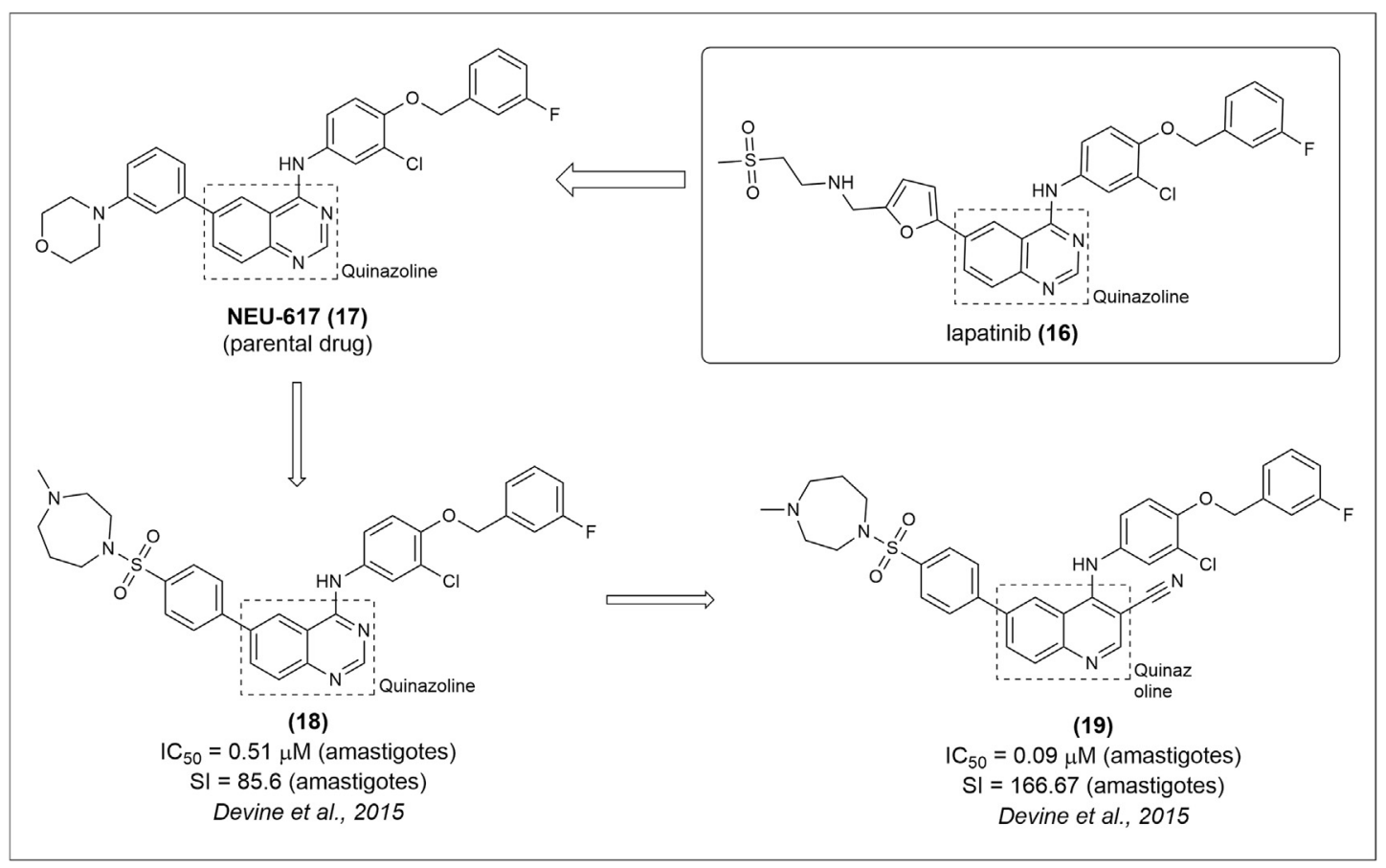

Fig. 5. Structures of lapatinib analogs (NEU-617). Novel lapatinib derivatives with antichagasic activity. 


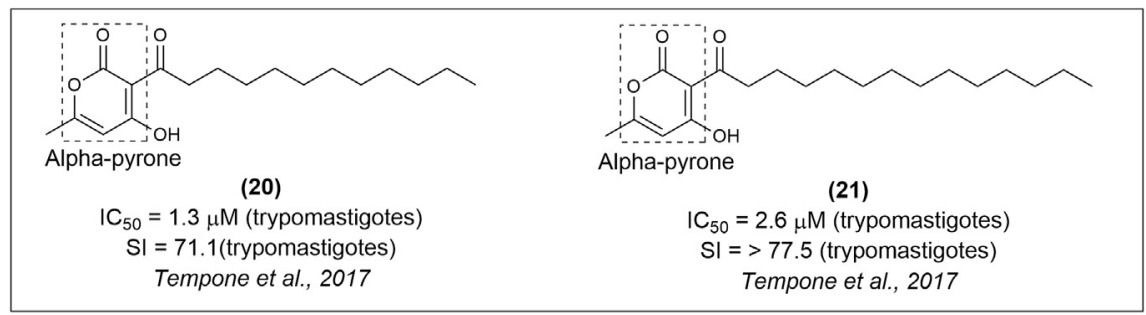

Fig. 6. Structure alpha-pyrone analogs. Alpha-pyrone derivatives active against trypomastigotes of $T$. cruzi.

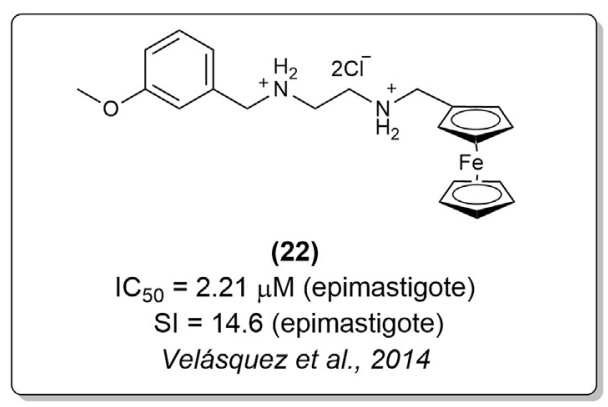

Fig. 7. Structures of ferrocenyl analogs. The most potent ferrocenyl derivative against T. cruzi.

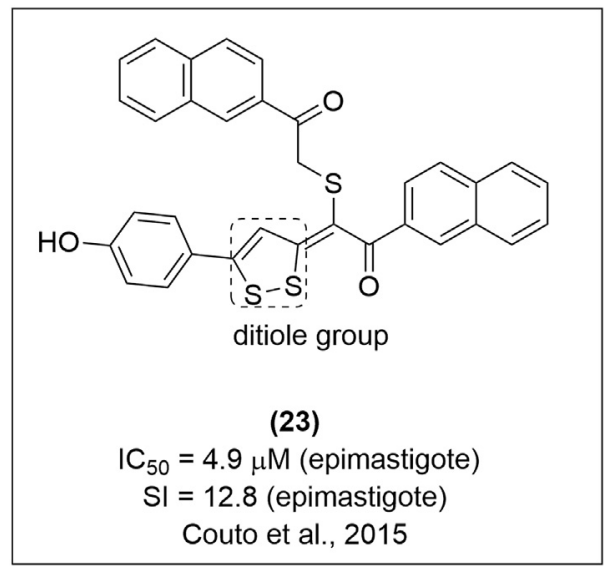

Fig. 8. Structure of dithiole analogs. Dithiole derivatives very effective against epimastigotes form of $T$. cruzi (Tulahuen 2 strain).

undergoes futile cycling, resulting in the production of superoxide anions [45]. Hall et al. described the role of trypanosomal type I NTRs in NFX activation [45], following which they exploited the drug target potential of NTRs by nitroheterocyclic agents [47-49]. The studies on some of the derivatives are presented in this section.

Triazole derivatives exhibit activity against the amastigotes forms of T. cruzi (Tulahuen C4 strains), with $\mathrm{IC}_{50}$ lower than $0.5 \mu \mathrm{M}$. The most actives analogs compounds $\mathbf{2 4}$ and $\mathbf{2 5}$ (Fig. 9) have an SI of 1194 and 2797, respectively. Earlier studies on their structural and functional relationships revealed that a chlorine atom in the para position is capable of increasing the biological activity. This effect was validated by the studies on the polar surface area [50]. In vivo evaluation using a murine model infected by $T$. cruzi showed that compounds $\mathbf{2 4}$ and $\mathbf{2 5}$ were able to reduce the parasitemic sanguineous concentration to sub-detectable levels. ADMET studies revealed that compound $\mathbf{2 4}$ crossed the plasma membrane of Caco2 cells and was stable in the presence of murine or human microsomes. Furthermore, compounds $\mathbf{2 4}$ and $\mathbf{2 5}$ were also evaluated against $T$. cruzi nitrorreductase, but no relevant antichagasic activity was seen [50].

A later study by the same group described another, more potent 3-nitrotriazole derivative. Compounds $\mathbf{2 6}$ and $\mathbf{2 7}$ (Fig. 9) have nanomolar $\mathrm{IC}_{50}$ values for the Tulahuen C4 strain of amastigotes $(8 \mathrm{nM}$ and $36 \mathrm{nM}$ respectively) and high SI values of 3615 and 1954, respectively. Compound $\mathbf{2 6}$ was 269 -fold and 4.5 fold more active than BZN and analog 27, respectively, making it the most active derivative. As with their previous study, the researchers observed that $T$. cruzi NTR enzymatic activity was not a determinant of antichagasic activity. All these compounds were capable of reducing the parasite load to undetectable levels in murine models infected with T. cruzi, indicating that these compounds are promising new antichagasic drugs [51].

\subsection{Cruzain}

Cruzain is a lysosomal cysteine protease of $T$. cruzi and a key etiological factor of Chagas disease [52,53]. Cruzain is expressed in all life cycle stages of the parasite and performs various biological functions [52]. Studies have shown the involvement of this enzyme in intracellular replication and differentiation of the epimastigotes to the infectious metacyclic form, immune evasion and hostparasite interactions [54].

Therefore, cruzain is a highly relevant therapeutic target and cruzain inhibitors have been developed by various research groups. A research group designed and synthesized several analogs of 8chloro- $\mathrm{N}$-(3-morpholinopropyl)-5H-pyrimido [5,4-b]indol-4amine and screened them for antichagasic activity. The analogs consisted of indole, pyrimidine, quinoline, aniline, and pyrrole derivatives. The 4-aminoquinoline analogs showed the most potent anti-cruzain activity with $\mathrm{IC}_{50}$ values ranging from 15 to $125 \mu \mathrm{M}$, and were also selective for the parasitic proteases. Compound $\mathbf{2 8}$ $\left(\mathrm{IC}_{50}=15 \mu \mathrm{M}\right)$ (Fig. 10), the best anti-cruzain compound, was also active against the trypomastigote form of $T$. cruzi (Tulahuen strain) $\left(\mathrm{IC}_{50}=67.7 \mu \mathrm{M}\right)$ demonstrating a high correlation between enzyme inhibition and anti-parasitic activity, but showed a low selectivity index ( $\mathrm{SI}=1.8)$. The pyrimidine analog 29 (Fig. 10) was the most active and selective compound ( $\mathrm{IC}_{50}=3.1 \mu \mathrm{M} ; \mathrm{SI}=128$ ) against the parasite, but was inactive against cruzain; therefore, requiring further studies to elucidate the mechanism of its action along with in vivo studies [55].

Another group identified a new class of imidazoles through computational screening, followed by the synthesis and biological evaluation. The most active compound $\mathbf{3 0}$ (Fig. 10) showed a high trypanocidal activity against the epimastigote form of $T$. cruzi of three different strains (Tulahuen 2, CL-clone B5 and Y), with $\mathrm{IC}_{50}$ values of $4.5 \mu \mathrm{M}, 3.6 \mu \mathrm{M}$, and $16.9 \mu \mathrm{M}$ respectively. Furthermore, the compound $\mathbf{3 0}$ was also active against the amastigotes of T. cruzi CL-clone B5 strain with an $\mathrm{IC}_{50}$ of $19.9 \mu \mathrm{M}$. In addition, the compound did not show any mutagenic activity in Ames' test. The 


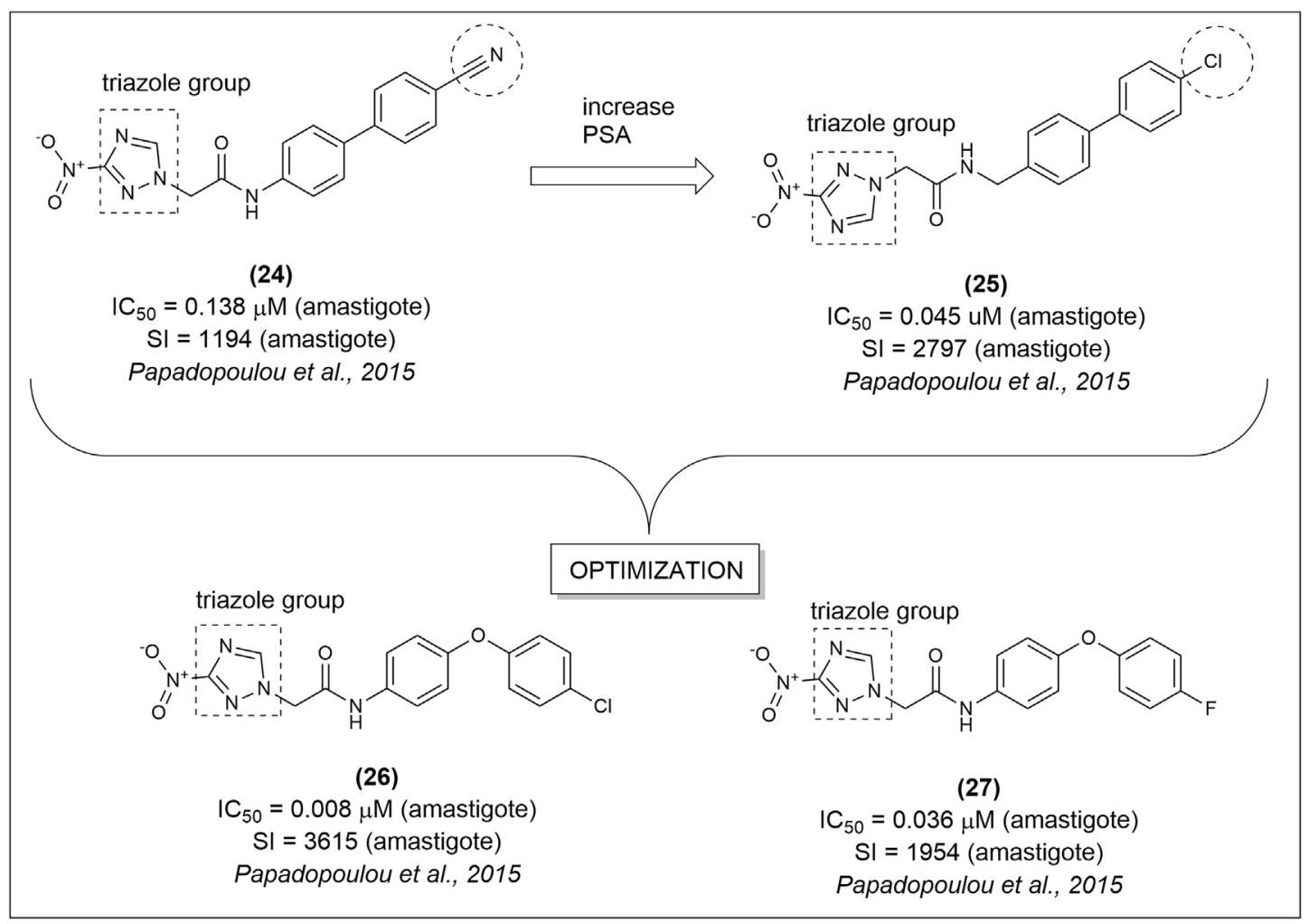

Fig. 9. Structures of 3-nitrotriazole analogs. The best nitrotriazole derivatives active against amastigotes form of $T$. cruzi.

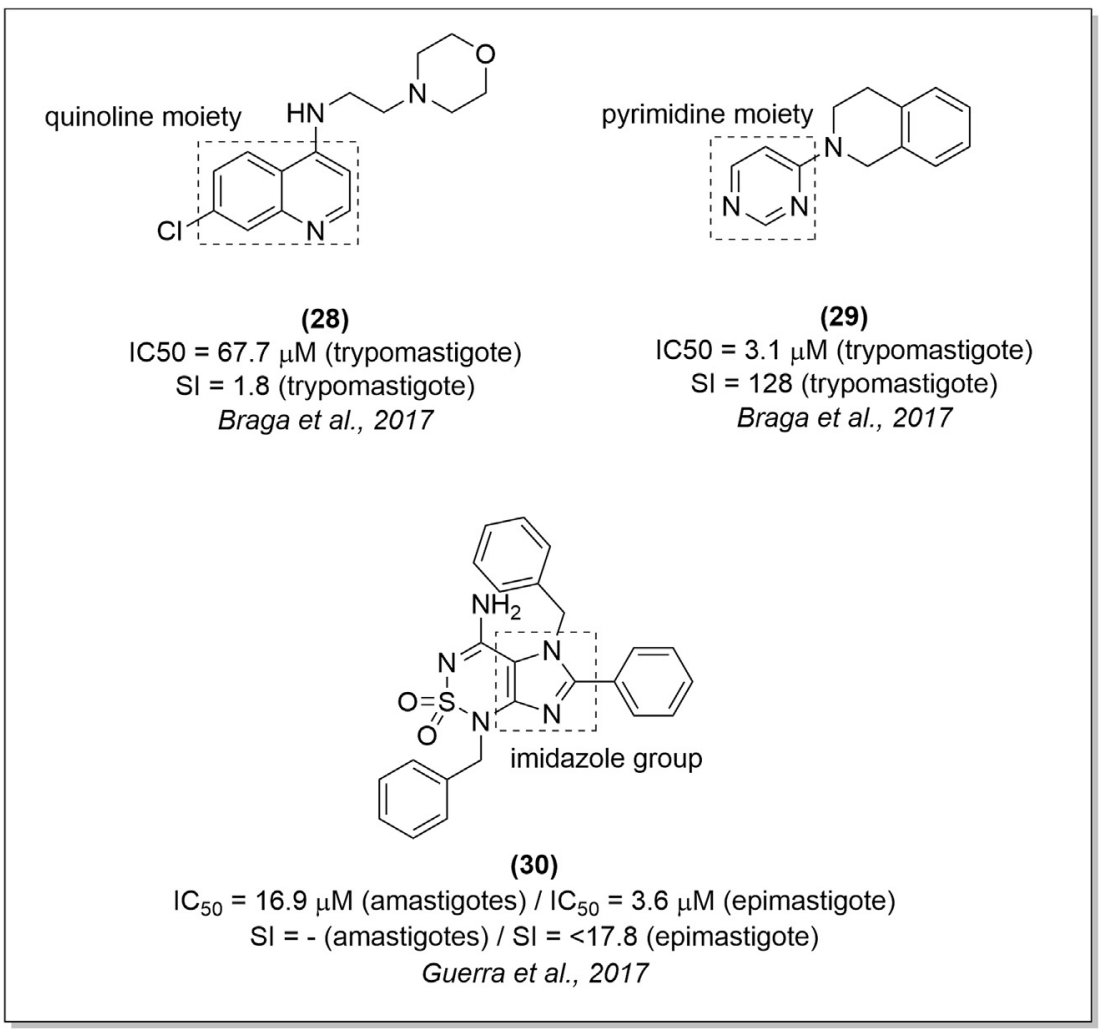

Fig. 10. Structures of quinoline, pyrimidine, and imidazole analogs. Quinoline, pyrimidine and imidazole derivatives active against $T$. cruzi. 
cruzipain inhibitory assay was also evaluated $\left(\mathrm{IC}_{50}=81 \pm 4 \mu \mathrm{M}\right)$, indicating a possible mechanism of action. In vivo assay with $T$. cruzi Y strain showed that compound $\mathbf{3 0}$ was also a potent trypanocidal analog during the acute phase of Chagas disease [56].

\subsection{Mitochondrial alterations}

Mitochondria are important cellular organelles involved in cellular redox, ATP synthesis, calcium homeostasis, nutrient oxidation, and apoptosis [57,58]. Hydrogen peroxide is the main oxidative species produced in mitochondria and is related to cytosol signaling in oxidative processes. Mitochondrial deregulation can lead to an increase in reactive oxygen species (ROS), resulting in cytotoxicity and death $[59,60]$. T. cruzi has unique mitochondria that contain kinetoplasts and highly compact networks of mitochondrial DNA that account for approximately $30 \%$ of the total genome [61]. This feature makes the mitochondria an important target in the development of new antichagasic agents.

One study evaluated the in vitro trypanocidal activity of 4nitrobenzaldehyde thiosemicarbazone (31) (Fig. 11), an S(-)-limonene derivative. The researchers discovered a potent activity of this compound against the trypomastigote $\left(\mathrm{IC}_{50}=1.43 \mu \mathrm{M}\right.$; $\mathrm{SI}=26.2)$ and amastigote $\left(\mathrm{IC}_{50}=11.84 \mu \mathrm{M} ; \mathrm{SI}=11.6\right)$ forms of $T$ cruzi (Y strain). Compound $\mathbf{3 1}$ induced mitochondrial alterations like cytoplasmic vacuolization, loss of membrane potential, and increase in free radical formation in the epimastigotes and trypomastigotes [62].

In another study, the antichagasic activity of four C-4 functionalized azalactone derivatives was evaluated. The most potent compound was 32 (Fig. 11), with an $\mathrm{IC}_{50}=33 \mu \mathrm{M}$ and $\mathrm{SI}=6.74$ against the epimastigote form of $T$. cruzi, and a 3-fold higher potency against $T$. cruzi amastigotes $\left(\mathrm{IC}_{50}=2.34 \mu \mathrm{M}\right.$ and $\left.\mathrm{SI}=95.04\right)$ compared to BZN. Flow cytometry and electron microscopy revealed a significant decrease in mitochondrial membrane potential and in the size of epimastigotes, without any damage to the plasma membrane. Based on their findings, the researchers

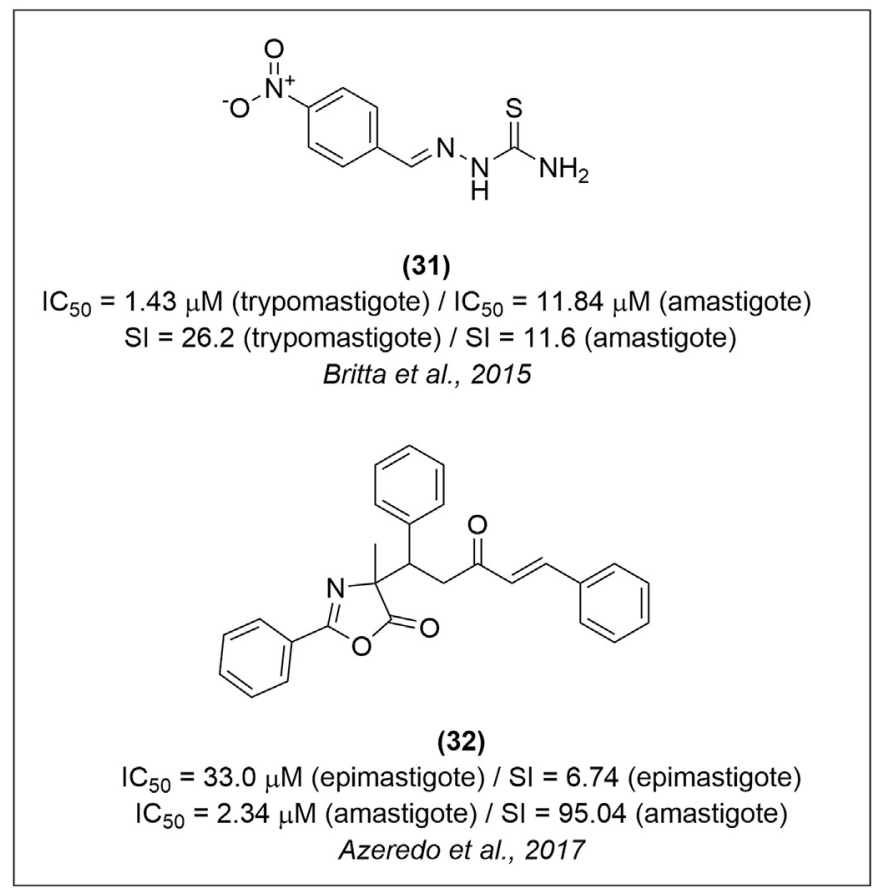

Fig. 11. Structures of nitrobenzaldehyde thiosemicarbazone and azalactone derivatives. Some compounds are described as possible mitochondrion target analogs. recommended the molecular modifications of this analog in developing new antichagasic lead compounds [63].

New antichagasic agents were obtained by linking gallic acid derivatives with lipophilic properties and the triphenylphosphonium (TPP+) moiety to target the small molecules on T. cruzi mitochondria. The researchers obtained two highly active compounds against trypomastigotes ( $\mathrm{Y}$ strain), $\mathbf{3 3}\left(\mathrm{EC}_{50}=1 \mu \mathrm{M}\right)$ and $\mathbf{3 4}$ $\left(\mathrm{EC}_{50}=1 \mu \mathrm{M}\right)$ (Fig. 12), which were more active than NFX. Compounds 33 and 34 were also more selective and were capable of modifying the mitochondrial membrane potential that leads to pore formation, indicating their potential in the development of new antichagasic analogs [64].

\subsection{Heme peroxidation}

Heme, or ferroprotoporphyrin, is involved in many biological processes such as respiration, detoxification, oxygen transport, cellular signaling, antioxidant gene expression, metabolism, and energy production. Heme breakdown produces free radicals that damage lipids, DNA, and proteins. T. cruzi requires heme from the host's blood for epimastigote multiplication through the redox mechanism, and blocking this pathway can potentially inhibit the epimastigotes [65,66].

Quinoline derivatives are nitrogen heterocyclic compounds that form complexes with heme, and are known for their activity against Plasmodium, Leishmania, T. cruzi, bacteria, and even in cancer [67-71]. Researchers have evaluated the activity of a series of 4arylaminoquinoline-3-carbonitrile derivatives against all forms of T. cruzi, and obtained compound 35 (Fig. 13) that was active against epimastigotes when combined with hemin, with higher potency than $\mathrm{BZN}\left(\mathrm{IC}_{50}=<1 \mu \mathrm{M}\right.$, SI $=>111.1$ ). In addition, $10 \mu \mathrm{M}$ of this compound inhibited 65\% of amastigotes growth after $72 \mathrm{~h} \mathrm{[72].}$ High-performance liquid chromatography analysis showed that heme is enzymatically converted to biliverdin, thus favoring heme oxygenase activity in the parasite. The authors also suggested that the formation of heme-quinoline $\mathbf{3 5}$ complex could be attributed to

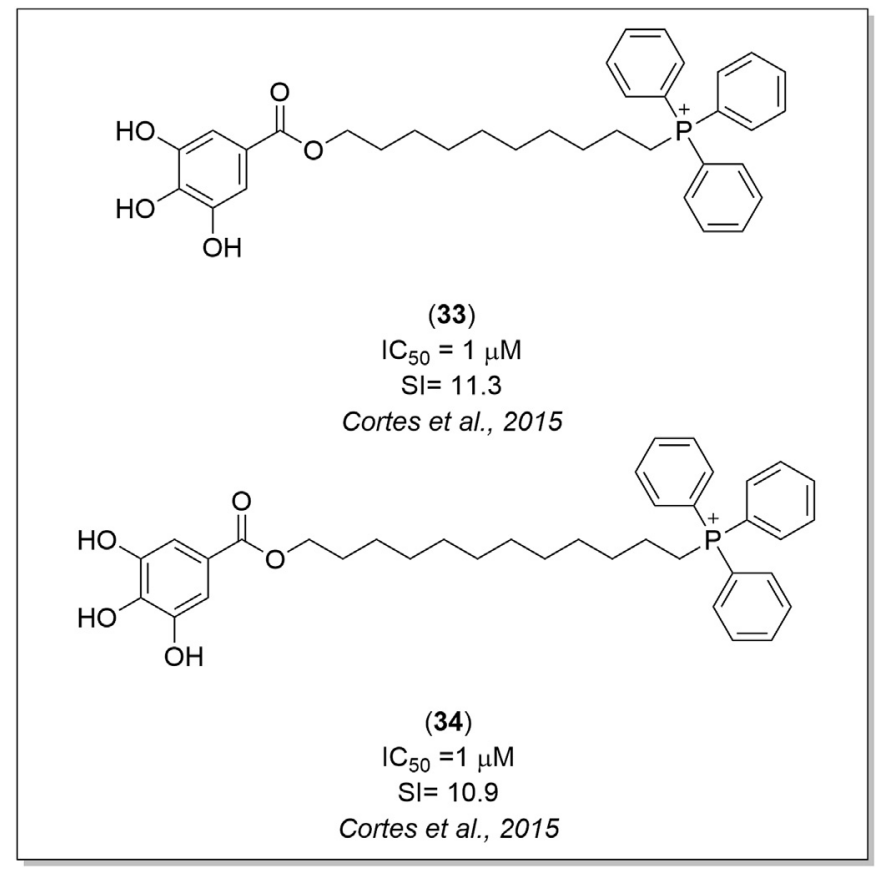

Fig. 12. Structures of triphenylphosphonium analogs. This is a class that provoke alterations in T. cruzi mitochondrion. 
the decrease in available heme levels and increase in the production of reactive oxygen species, leading to parasite death [72].

\subsection{Iron superoxide dismutase (Fe-SOD)}

Superoxide dismutase (SOD) catalyzes the transfer of superoxide anion through dismutation to oxygen or hydrogen peroxide, and is a key enzyme that neutralizes the toxicity of free oxygen radicals [73]. T. cruzi has four Fe-SODs that are produced in the mitochondrion (TcSODA and C), cytosol (TcSODB1), and glycosomes (TcSODB1-2) [74]. Since T. cruzi SODs are different from their human counterparts, they are often the targets for drug discovery [75].

By repurposing existing screening libraries, some researchers synthesized and evaluated a series of antichagasic arylaminoketone derivatives. Their study was based on previous ${ }^{1} \mathrm{H}$ - Magnetic Nuclear Resonance $\left({ }^{1} \mathrm{H}\right.$ NMR) results that indicated these analogs exerted their effects via Fe-SOD. The compounds 36, 37, 38 and 39 (Fig. 14) showed higher antichagasic activity and less in vitro cytotoxicity when compared to BZN in three different T. cruzi strains (SN3, Arequipa, and Tulahuen) against all three parasitic forms (Fig. 14), with SI over 17. These compounds were selected and evaluated in vivo during the acute phase of the disease, and only compound 38 did not result in the reactivation of blood parasitemia during the immunosuppression cycles [76], in addition to inhibiting Fe-SOD in vitro. The authors hypothesized that the fluorine atoms and nitro group of the compound interacted with the Lys35, Gln68 and Asn 117 of the enzyme docking site through hydrophobic interactions. The compounds do no interact with the metal of binding site, which can inhibit the molecule to have access to the active site of Fe-SOD [76].

\subsection{Trypanothione reductase}

Trypanothione reductase (TR) is an attractive chemotherapeutic target for developing new anti-trypanosome drugs since it is unique to the Trypanosomatidae family and absent from mammalian cells [77-79]. TR is a flavoprotein consisting of a spermidine moiety linked to two glutathione molecules. It catalyzes the NADPH dependent reduction of trypanothione disulfide to trypanothione, and acts as an important antioxidant defending the parasite from oxidative stress [78-81].

Some researchers have designed and synthesized, through the microwave-irradiated synthesis, several isoxazole analogs based on the structure of the natural lignans, grandisin, and veraguensin, which have shown potent action against trypomastigotes and intracellular amastigotes of $T$. cruzi (Tulahuen strain). The main

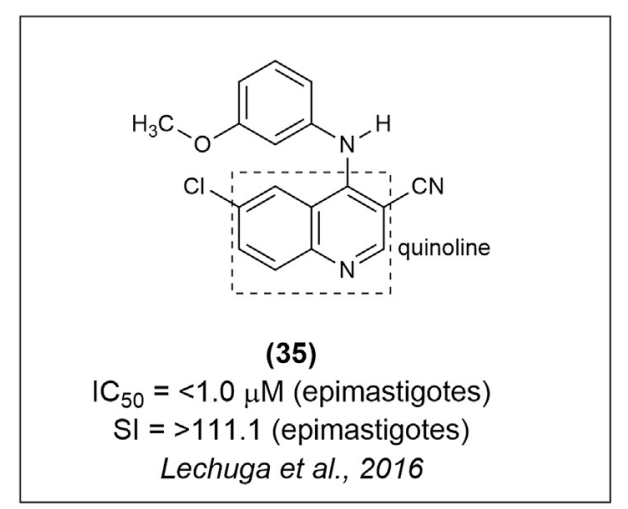

Fig. 13. Structures of quinoline derivatives. Analog $\mathbf{3 5}$ described as an interferent of heme peroxidation of $T$. cruzi. derivatives were compounds 40, 41 and $\mathbf{4 2}$ (Fig. 15) that showed low inhibitory concentrations for the amastigote forms of $T$. cruzi with $\mathrm{IC}_{50}=5.26 \mu \mathrm{M}(\mathrm{SI}=13.3), 1.74 \mu \mathrm{M}(\mathrm{SI}=46.7)$ and $1.13 \mu \mathrm{M}$ $(S I=160.9)$, respectively, and none of them were active against the trypomastigotes form. The enzymatic assay results suggested that the isoxazoles can act by the mechanisms independent of trypanothione reductase [82].

\subsection{Squalene synthase (SQS)}

T. cruzi requires endogenous sterols like ergosterol and its analogs for growth and survival [83]. Ergosterol is essential for the maintenance of plasma membrane and performs functions analogous to that of cholesterol in human cells [84]. Ergosterol biosynthesis requires squalene synthase (SQS) which catalyzes the reductive dimerization of two farnesyl-pyrophosphate (FPP) molecules in a two-step process to form squalene [83].

Some researchers synthesized new isosteric analogs based on compound 43 (4-phenoxyphenoxyethyl thiocyanate) that was previously described as a good non-competitive allosteric inhibitor of $T$. cruzi SQS [83,85], in order to understand the effect of different atoms on the activity of this inhibitor [86]. The activity of these analogs were tested against T. cruzi amastigote (CL strain) overexpressing a tdTomato red fluorescent protein, and their toxicity and SI were tested in Vero cells. The compounds with selenocyanate moiety, especially derivative $\mathbf{4 4}$ (Fig. 16), were extremely potent inhibitors of $T$. cruzi proliferation, almost 50 times more potent and 100 times more selective than 43. Compound 45 (Fig. 16), also a selenocyanate derivative with a fluorophenoxy group, was also a very effective inhibitor of the parasite with very low toxicity [86].

Compounds $\mathbf{4 3}$ and $\mathbf{4 4}$ were selected and subjected to in silico analyses with crystallography data from the Cambridge Structural Database (CSD). The results indicated that it was the presence of Se and not $S$ that increased the interaction between the compounds and SQS [86].

\subsection{Farnesyl diphosphate synthase (FPPS)}

Another enzyme that has been considered as a valid target against various parasitic diseases is farnesyl diphosphate synthase (FPPS) [87]. It is involved in the mevalonate pathway [88]. FPPS catalyzes the condensation of isopentenyl diphosphate (IPP) and dimethylallyl diphosphate (DMAPP) to form geranyl diphosphate (GPP), and subsequently farnesyl diphosphate (FPP) [89]. FPP is the substrate for enzymes catalyzing the first committed step in the biosynthesis of sterols, ubiquinones, dolichols, heme group, and prenylated proteins [87]. FPP is an important branching point in the mevalonate pathway leading to protein farnesylation, and biosynthesis of dolichols and sterols such as cholesterol and ergosterol [89]. Inhibition of FPPS blocks farnesyl pyrophosphate and geranylgeranyl pyrophosphate synthesis [90].

Bisphosphonates are potent inhibitors of bone resorption and are used to treat several bone disorders such as osteoporosis, Paget's disease, hypercalcemia, and tumor bone metastases. The selective antiparasitic action of bisphosphonates is likely due to the presence of acidocalcisomes, which facilitate the accumulation of bone minerals on account of similar composition [87-92].

Researchers have synthesized and evaluated 2alkylmercaptoethyl-1,1-bisphosphonate derivatives against T. cruzi in the presence of FPPS. The results showed that sulfur-containing bisphosphonic acids with long aliphatic chains were effective against the amastigote form of $T$. cruzi (CL strain) overexpressing a tdTomato RFP, with potent activity against TcFPPS. The most active compounds $\mathbf{4 6}$ and $\mathbf{4 7}$ (Fig. 17) were also the most potent inhibitors 
<smiles>O=C(CCN1CCN(c2ccc([N+](=O)[O-])cc2)CC1)c1csc2ccccc12</smiles>

(36)

$I C_{50}=11.7 \mu \mathrm{M}$ (amastigote of Arequipa strain) $\mathrm{SI}=143$ (amastigote)

Moreno-Viguri et al., 2016<smiles>CC(C)(C)CCC(=O)c1csc2ccc(F)cc12</smiles>

(38)

$\mathrm{IC}_{50}=4.9 \mu \mathrm{M}$ (amastigote Tulahuen strain)

$\mathrm{SI}=155$ (amastigote)

Moreno-Viguri et al., 2016

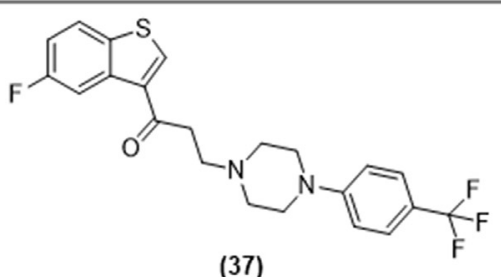

$\mathrm{IC}_{50}=8.7 \mu \mathrm{M}$ (amastigote SN3 strain) $\mathrm{SI}=103$ (amastigote) Moreno-Viguriet al., 2016<smiles>O=C(CCN1CCN(c2ccc([N+](=O)[O-])cc2C(F)(F)F)CC1)c1csc2ccc(F)cc12</smiles>

$\mathrm{IC}_{60}=10.8 \mu \mathrm{M}$ (amastigote of Arequipa strain) $\mathrm{SI}=263$ (amastigote) Moreno-Viguri et al., 2016

Fig. 14. Structures of arylaminoketones derivatives. The best arylaminoketones analogs were described by Moreno-Viguri et al. (2016).

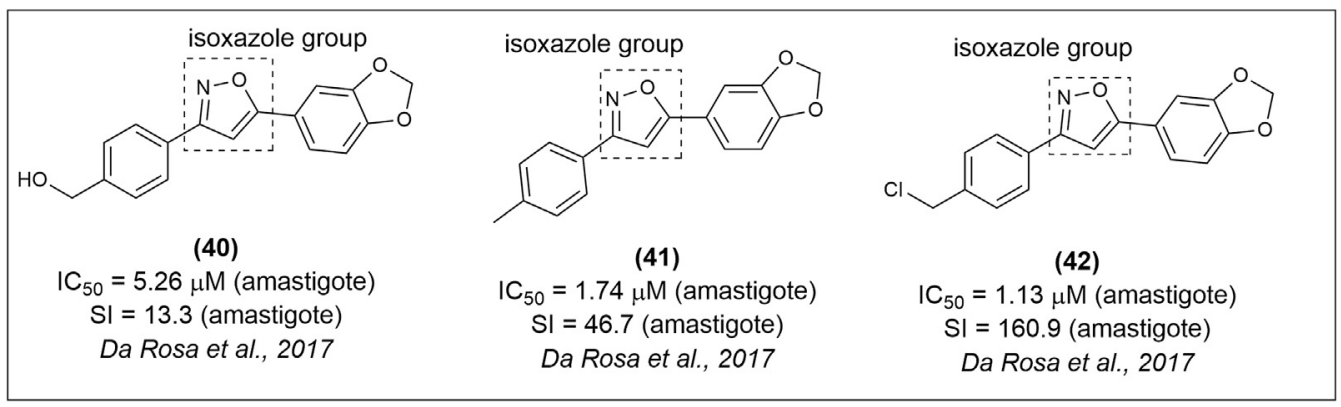

Fig. 15. Structures of isoxazoles derivatives. Isoxazoles analogs active against amastigotes form of T. cruzi (Tulahuen strain).

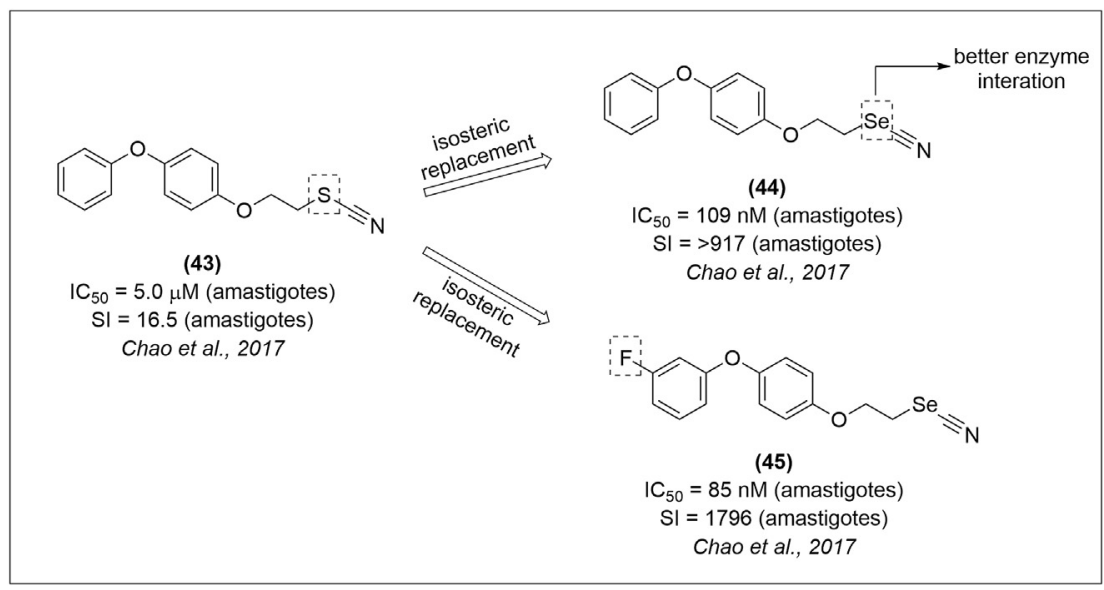

Fig. 16. Structures of thiocyanate derivatives. The isosteres of compound $\mathbf{4 3}$ active against T. cruzi. 


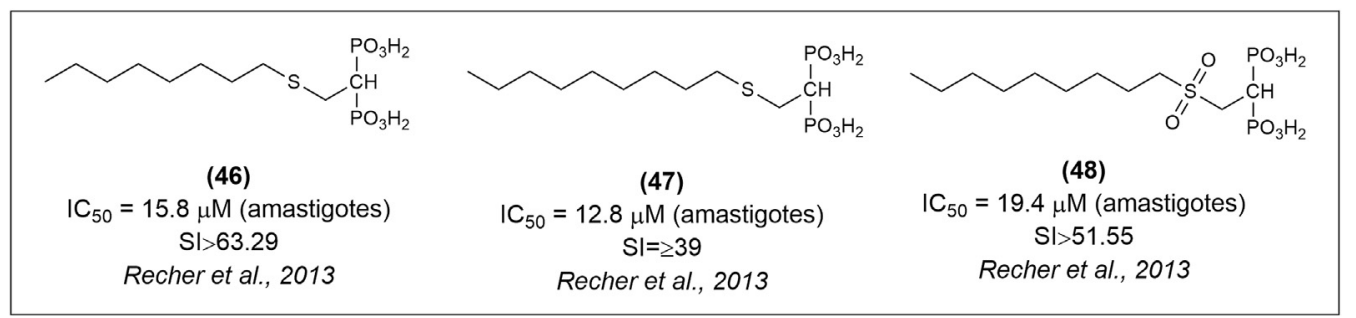

Fig. 17. Structures of bisphosphonate analogs. The best bisphosphonate derivatives described for Recher et al., 2013.

of FPPS. Analog 48 also showed good activity against the amastigotes but was not a good inhibitor of the enzyme (above $10 \mu \mathrm{M}$ could promote $50 \%$ inhibition) [93].

\subsection{Physico-chemical properties and selective indices of the most active compounds}

Since the physicochemical properties of a compound are correlated with its biological activity [94-99], we have summarized some properties of the most active compounds such as lipophilicity, number of hydrogen bond acceptors and donors, number of rotatable bonds, molecular weight and surface area (Table S1. supplementary material).

Lipophilicity $(\operatorname{cog} P)$ is a vital property in the context of drug discovery and development since it affects the solubility, permeability, and bioavailability of compounds [100-104]. In general, all of the active compounds reviewed here exhibit lipophilicity and molecular weight values range from 0.7 to 9.1 and 211.2 to 656.2, respectively. Fig. 18 describes the correlation between the SI values and $\operatorname{cog} P$ for the most active compounds. Nine compounds exhibited SI values over 900 and $\operatorname{cLog} P$ values from 2.7 to 5.68 when tested against different T. cruzi strains like Sylvio X-10 (3), Tulahuen C4 (4), and CL (2).

\section{Current drugs under clinical trials and perspectives}

Azole analogs such as ketoconazole, itraconazole, fluconazole, posaconazole, and ravuconazole are the main inhibitors of sterol 14- $\alpha$ demethylase (CYP51). Crystallographic studies (PDB code: 3K10) have shown the highest enzyme inhibitory effect and affinity of Posaconazole (49) (Fig. 19). This compound is effective against both the epimastigote and amastigote forms of T. cruzi, and also

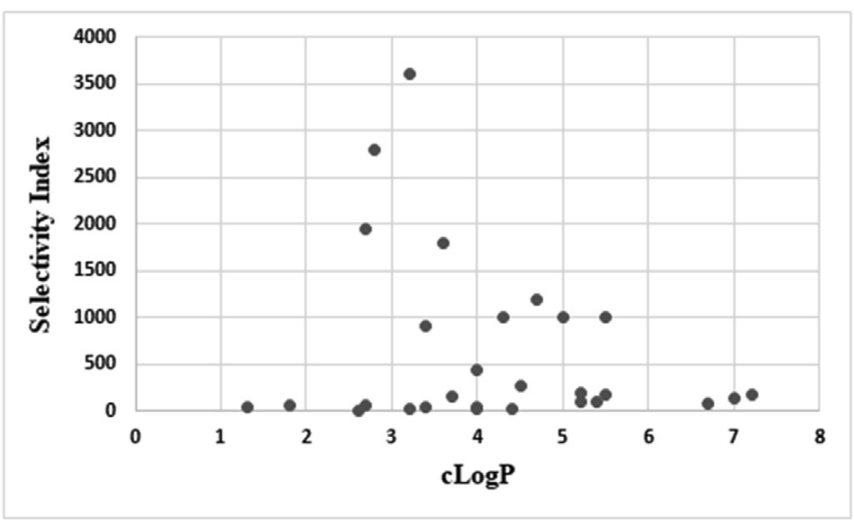

Fig. 18. Correlation between $\mathrm{SI}\left(\mathrm{IC}_{50} / \mathrm{CC}_{50}\right)$ values and $\operatorname{cLog} P$ for the compounds. $\operatorname{cLog} P$ : calculated partition coefficient. shows good activity against the drug-resistant strains like $\mathrm{Y}$ and Colombia [105-110]. In 2015, a study reported its limited capacity for "curing" Chagas disease through highly sensitive in vivo bioluminescence imaging assay. Clinical studies in Argentina, Bolivia, and Spain compared the effects of posaconazole and BZN in adults with chronic Chagas disease [111], and showed lower activity of this new drug relative to BZN [112]. A clinical trial investigating the effects of posaconazole and BZN co-administration is currently being conducted by Merck.

Ravuconazole (50) and its prodrug E-1224 (51) (Fig. 18) have also demonstrated high in vitro efficacy against $T$. cruzi $[113,114]$ but the low bioavailability and half-life of the former discouraged further evaluation. Therefore, only the prodrug was selected for clinical trials [113-115], and the results showed that compared to the standard drug, this compound did not remain effective after one year of treatment [116]. Adverse effects were also observed at high doses, leading to the cessation of the treatment in phase II.

K777 (52) (Fig. 20) is a vinyl sulfone cysteine protease inhibitor, which has shown potent inhibition of cruzain [117-119], and has a complex structure as per crystallography (PDB code: 2OZ2). In addition, it is effective against the epimastigote and amastigote forms of $T$. cruzi and reduced blood parasitemia in animal models, thereby prolonging their survival [120]. However, K777d did not proceed to clinical trials due to its high hepatotoxicity.

Hydroxymethylnitrofurazone (NFOH) (53) (Fig. 20) is a new drug candidate that has shown high in vitro and in vivo trypanocidal activity in both trypomastigotes and amastigotes, along with a lower mortality rate in the acute phase compared to BZN [121-123]. Similar concentrations of nitrofurazone and NFOH, respectively, inhibited $30 \%$ and $60 \%$ cruzain (PDB code: $1 \mathrm{ME} 4$ ) [124]. Davies and co-workers (2014) evaluated the short-term (21 days) and long-term (60 days) hepatoxicity of NFOH $(150 \mathrm{mg} / \mathrm{kg} /$ day) in an acute phase animal model treated for five days postinfection, and noted lower liver infiltration compared to BZN treatment but no significant alteration in other hepatic markers [125]. Using transgenic T. cruzi Brazil (Luc strains) expressing the firefly luciferase, researchers have reported $78.5 \%$ of the trypanocidal activity after four days of NFOH treatment (50 mg/kg) [126]. These encouraging studies indicate that NFOH can be a potential candidate for clinical studies.

Intensive research on the discovery of new analogs for the treatment of Chagas disease has been undertaken. The data from clinical trials indicate that most of these drugs are new diagnostic methodologies or new formulations with standard treatment drugs for children including old (known) and new (unknown) drugs. The treatment to Chagas disease is still a challenge in medicinal chemistry. Among the 58 clinical trials on Chagas disease, only 40 are interventional studies at different stages of completion: completed (17), unknown (9), recruiting (6), not yet recruiting (3), active not recruiting (2), terminated (2), and enrolling by invitation (1) (Fig. 21, Table S2. Supplementary material). 


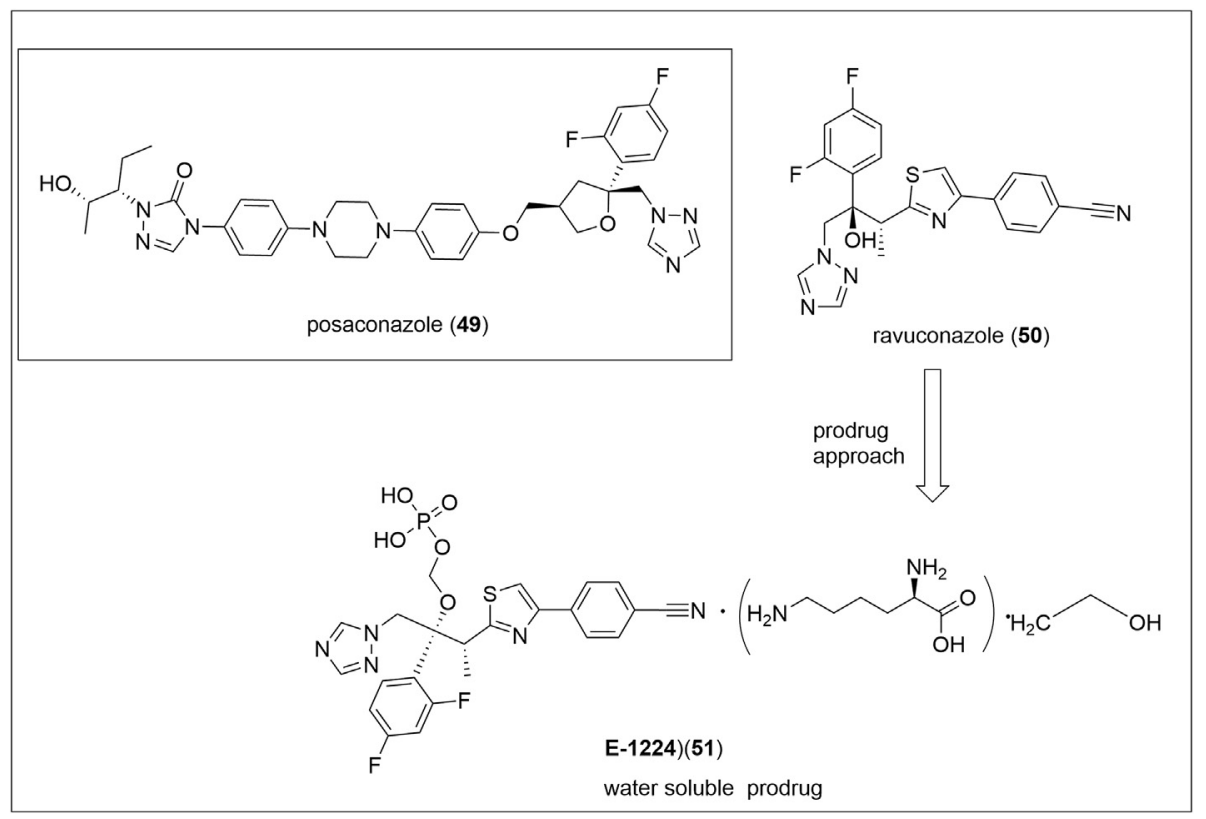

Fig. 19. Structures of azole analogs: Azole derivatives active against T. cruzi.

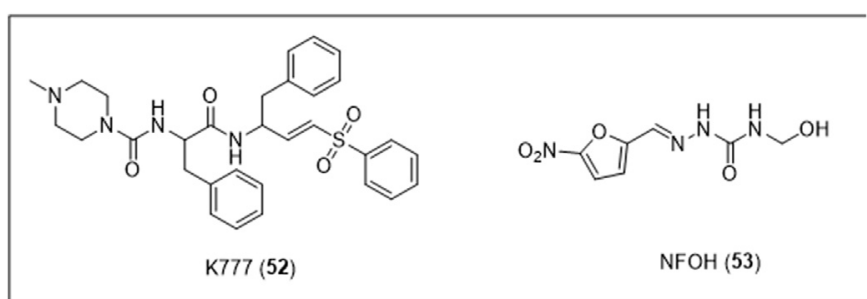

Fig. 20. Structures of K777 (52) and hydroxymethylnitrofurazone (NFOH) (53). Novel candidates against Chagas disease.

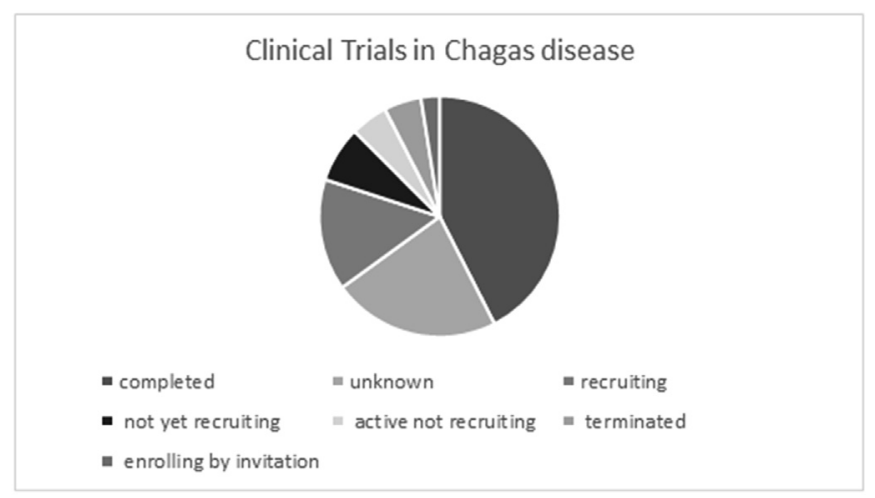

Fig. 21. The ongoing clinical trial on Chagas disease: 40 studies are interventional (number of studies): completed (17), unknown (9), recruiting (6), not yet recruiting (3), active not recruiting (2), terminated (2), and enrolling by invitation (1).

\section{Conclusions}

Despite the large number of new molecules that have been identified and synthesized and a greater insight on the molecular biology of T. cruzi, which has further increased the pool of potential targets, the development of novel antichagasic drugs remains a difficult task. This is largely due to the lack of interest by the pharmaceutical companies, failure of pre-clinical and clinical trials, and the socio-economic disparities in developing countries. Strategies aiming to develop a partnership between the industry, academia and non-profit organizations could help accelerate the drug development process. However, in spite of this bleak scenario, several promising antichagasic compounds have been described in recent years. The different chemotypes described in this review can provide the necessary prototypes for further development of new drugs against $T$. cruzi.

\section{Authors' contribution}

All authors contributed equally for the manuscript.

\section{Conflicts of interest}

The authors declare no conflict of interest.

\section{Acknowledgment}

The authors would like to thank the Programa de Apoio ao Desenvolvimento Científico da Faculdade de Ciências Farmacêuticas da UNESP (PADC/FCF-UNESP) and Coordenação de Aperfeiçoamento Pessoal de Nível Superior (CAPES) for research fellowships and financial assistance.

\section{Appendix A. Supplementary data}

Supplementary data related to this article can be found at https://doi.org/10.1016/j.ejmech.2018.06.040.

\section{References}

[1] WHO, Chagas disease in Latin America: an epidemiological update based on 2010 estimates, Geneva World Heal. Organ 90 (2015) 33-44.

[2] WHO (World and Health Organization), Neglected tropical diseases. http:// www.who.int/neglected_diseases/diseases/en/, 2017. (Accessed 18 December 2017).

[3] W. Feasey, Nick Wansbrough-Jones, Mark Mabey, C.W. David, Solomon, Anthony, neglected tropical diseases, Br. Med. Bull. 93 (2010) 179-200, https://doi.org/10.1093/bmb/ldp046. 
[4] J.P. Cohen, G. Sturgeon, A. Cohen, Measuring progress in neglected disease drug development, Clin. Therapeut. 36 (2014) 1037-1042, https://doi.org/ 10.1016/j.clinthera.2014.05.004.

[5] G. Malafaia, A.S.D.L. Rodrigues, Centenário do descobrimento da doença de Chagas: desafios e perspectivas, Centen. Do Descob, Da Doença Chagas Desafios E Perspect 43 (2010) 483-485, https://doi.org/10.1590/S003786822010000500001.

[6] C. Chagas, Nova tripanozomiaze humana: estudos sobre a morfolojia e o ciclo evolutivo do Schizotrypanum cruzi n. gen., n. sp., ajente etiolojico de nova entidade morbida do homem, Mem. Inst. Oswaldo Cruz 1 (1909) 159-218, https://doi.org/10.1590/S0074-02761909000200008.

[7] J.R. DIAS, J.C.P. COURA, in: Clínica e terapêutica da doença de Chagas, uma abordagem prática para o clínico geral, Cad. Saúde Pública, Rio de Janeiro, 1997, p. 486

[8] Z. ANDRADE, Patologia da Doença de Chagas, in: G. Koogan (Ed.), Trypanos, Cruzi E Doença Chagas., 2॰ ${ }^{\circ}$ Rio de Janeiro, 2000, pp. 379-388.

[9] P.A. Coura, R. José, Viñas, Chagas disease: a Latin American health problem becoming a world health problem, Nature 115 (2010) 14-21, https://doi.org/ 10.1016/j.actatropica.2009.11.003.

[10] Q. Liu, X.N. Zhou, Preventing the transmission of American trypanosomiasis and its spread into non-endemic countries, Infect. Dis. Poverty 4 (2015) 1-11, https://doi.org/10.1186/s40249-015-0092-7.

[11] WHO (World and Health Organization), Chagas disease - Epidemiology. http://www.who.int/chagas/epidemiology/en/, 2017. (Accessed 28 December 2017).

[12] S. Andrade, F.A. Carneiro, A. de Souza, E. de Lima, Z. Andrade, Influence of treatment with immunosuppressive drugs in mice chronically infected with Trypanosoma cruzi, Int. J. Exp. Pathol. 78 (6) (1997) 391-399.

[13] N.N. Taniwaki, V.M. Gonçalves, J.K. Romero, C.V. Da Silva, S. Da Silva, R.A. Mortara, Trypanosoma cruzi strains in the Calomys callosus: parasitemia and reaction of intracellular forms with stage-specific antibodies in the acute and chronic phase of infection and after immunosuppression, Parasitol. Res. 109 (2011) 431-440, https://doi.org/10.1007/s00436-011-2273-z.

[14] J.D. Maya, M. Orellana, J. Ferreira, U. Kemmerling, R. López-Muñoz, A. Morello, Chagas disease: present status of pathogenic mechanisms and chemotherapy, Biol. Res. 43 (2010) 323-331, https://doi.org/10.4067/S071697602010000300009.

[15] WHO, Control of Chagas disease : second report of the WHO expert committee World Health Organization (2000: Brasilia, Brazil), Geneva World Heal. Organ 905 (2002) 109.

[16] P. Pan, A.B. Vermelho, G. Capaci Rodrigues, A. Scozzafava, M.E.E. Tolvanen, S. Parkkila, C. Capasso, C.T. Supuran, Cloning, characterization, and sulfonamide and thiol inhibition studies of an a-Carbonic Anhydrase from trypanosoma cruzi, the causative agent of chagas disease, J. Med. Chem. 56 (2013) 1761-1771, https://doi.org/10.1021/jm4000616.

[17] A.L.S.S. de Andrade, F. Zicker, R.M. de Oliveira, S.A. Silva, A. Luquetti, L.R. Travassos, I.C. Almeida, S.S. de Andrade, J.G. de Andrade, C.M.T. Martelli, Randomised trial of efficacy of benznidazole in treatment of early Trypanosoma cruzi infection, Lancet 348 (1996) 1407-1413, https://doi.org/ 10.1016/S0140-6736(96)04128-1.

[18] S. Sosa-Estani, E. Segura, A. Ruiz, E. Velazquez, B. Porcel, C. Yampotis, Efficacy of chemotherapy with benznidazole in children in the indeterminate phase of Chagas' disease, Am. J. Trop. Med. Hyg. 59 (1998) 526-529.

[19] G.M.S. Da Silva, M.F.F. Mediano, P.E.A.A. Do Brasil, M.D.C. Chambela, D.J.A. Silva, A.S. De Sousa, S.S. Xavier, A.R. Da Costa, R.M. Saraiva, A.M. Hasslocher-Moreno, A clinical adverse drug reaction prediction model for patients with chagas disease treated with benznidazole, Antimicrob, Agents Chemother 58 (2014) 6371-6377, https://doi.org/10.1128/ AAC.02842-14.

[20] C.A. Morillo, J.A. Marin-Neto, A. Avezum, S. Sosa-Estani, A. Rassi Jr, F. Rosas, E. Villena, R. Quiroz, R. Bonilla, C. Britto, F. Guhl, E. Velazquez, L. Bonilla, B. Meeks, P. Rao-Melacini, J. Pogue, A. Mattos, J. Lazdins, A. Rassi, S.J. Connolly, S. Yusuf, Randomized trial of benznidazole for chronic chagas' Cardiomyopathy, N. Engl. J. Med. 373 (2015) 1295-1306.

21] D. Soy, E. Aldasoro, L. Guerrero, E. Posada, N. Serret, T. Mejía, J.A. Urbina, J. Gascón, Population pharmacokinetics of benznidazole in adult patients with Chagas disease, Antimicrob. Agents Chemother. 59 (2015) 3342-3349, https://doi.org/10.1128/AAC.05018-14.

[22] M.L. Fernandez, A.R. Riarte, M.E. Marson, G. Mastrantonio, J.C. Ramirez, A.G. Schijman, J. Altcheh, F.G. Bournissen, Pharmacokinetic and pharmacodynamic responses in adult patients with Chagas disease treated with a new formulation of benznidazole, Mem. Inst. Oswaldo Cruz 111 (2016) 218-221, https://doi.org/10.1590/0074-02760150401.

[23] A.M. Hasslocher-Moreno, P.E.A.A. do Brasil, A.S. de Sousa, S.S. Xavier, M.C. Chambela, G.M.S. da Silva, Safety of benznidazole use in the treatment of chronic Chagas' disease, J. Antimicrob. Chemother. 67 (2012) 1261-1266, https://doi.org/10.1093/jac/dks027.

[24] C.D. Fernandes, F.M. Tiecher, M.M. Balbinot, D.B. Liarte, D. Scholl, M. Steindel, A. Romanha, Efficacy of benznidazol treatment for asymptomatic chagasic patients from state of Rio Grande do Sul evaluated during a three years follow-up, Mem. Inst. Oswaldo Cruz 104 (2009) 27-32, https://doi.org/ 10.1590/S0074-02762009000100004.

[25] M.C. Andrade, M.D.F. Oliveira, A.T. Nagao-Dias, I.C.B. Coêlho, D.D.S. Cândido, E.C. Freitas, H.L.L. Coelho, F.S.M. Bezerra, Clinical and serological evolution in chronic Chagas disease patients in a 4-year pharmacotherapy follow-up: a preliminary study, Rev. Soc. Bras. Med. Trop. 46 (2013) 776-778, https:// doi.org/10.1590/0037-8682-1646-2013.

[26] J.A. Castro, M.M. deMecca, L.C. Bartel, Toxic side effects of drugs used to treat chagas' disease (American trypanosomiasis), Hum. Exp. Toxicol. 25 (2006) 471-479, https://doi.org/10.1191/0960327106het653oa.

[27] E. Chatelain, Chagas disease research and development: is there light at the end of the tunnel? Comput. Struct. Biotechnol. J. 15 (2017) 98-103, https:// doi.org/10.1016/j.csbj.2016.12.002.

[28] E. Chatelain, J.-R. Ioset, Phenotypic screening approaches for Chagas disease drug discovery, Expet Opin. Drug Discov. (2017) 1-43, https://doi.org/ 10.1080/17460441.2018.1417380.

[29] J.G. Moffat, F. Vincent, J.A. Lee, J. Eder, M. Prunotto, Opportunities and challenges in phenotypic drug discovery: an industry perspective, Nat. Rev. Drug Discov. 16 (2017) 531-543, https://doi.org/10.4018/jec.2011070104.

[30] D.C. Swinney, Phenotypic vs. target-based drug discovery for first-in-class medicines, Clin. Pharmacol. Ther. 93 (2013) 299-301, https://doi.org 10.1038/clpt.2012.236

[31] M.L. Sykes, V.M. Avery, Approaches to protozoan drug discovery: phenotypic screening. Miniperspectives series on phenotypic screening for antiinfective targets, J. Med. Chem. 56 (2013) 7727-7740, https://doi.org/10.1021/ jim4004279.

[32] G. Álvarez, J. Varela, P. Márquez, M. Gabay, C.E. Arias Rivas, K. Cuchilla G.A. Echeverría, O.E. Piro, M. Chorilli, S.M. Leal, P. Escobar, E. Serna, S. Torres, G. Yaluff, N.I. Vera de Bilbao, M. González, H. Cerecetto, Optimization of antitrypanosomatid agents: identification of nonmutagenic drug candidates with in vivo activity, J. Med. Chem. 57 (2014) 3984-3999, https://doi.org/ $10.1021 / j \mathrm{~m} 500018 \mathrm{~m}$

[33] G. Álvarez, J. Varela, E. Cruces, M. Fernández, M. Gabay, S.M. Leal, P. Escobar L. Sanabria, E. Serna, S. Torres, S.J.F. Thiel, G. Yaluff, N.I.V. De Bilbao, H. Cerecetto, M. González, Identification of a new amide-containing thiazole as a drug candidate for treatment of chagas' disease, Antimicrob. Agents Chemother. 59 (2015) 1398-1404, https://doi.org/10.1128/AAC.03814-14.

[34] J. Aubé, Drug repurposing and the medicinal chemist, ACS Med. Chem. Lett. 3 (2012) 442-444, https://doi.org/10.1021/ml300114c.

[35] M. Kaiser, L. Maes, L.P. Tadoori, T. Spangenberg, J.-R. Ioset, Repurposing of the open access Malaria Box for kinetoplastid diseases identifies novel active scaffolds against trypanosomatids, J. Biomol. Screen 20 (2015) 634-645, https://doi.org/10.1177/1087057115569155.

[36] A.M. Thompson, A. Blaser, B.D. Palmer, R.F. Anderson, S.S. Shinde, D. Launay, E. Chatelain, L. Maes, S.G. Franzblau, B. Wan, Y. Wang, Z. Ma, W.A. Denny, 6Nitro-2,3-dihydroimidazo[2,1-b][1,3]thiazoles: facile synthesis and comparative appraisal against tuberculosis and neglected tropical diseases, Bioorg. Med. Chem. Lett 27 (2017) 2583-2589, https://doi.org/10.1016 j.bmcl.2017.03.069.

[37] P. De Andrade, O.A. Galo, M.R. Carvalho, C.D. Lopes, Z.A. Carneiro, R. SestiCosta, E.B. De Melo, J.S. Silva, I. Carvalho, 1,2,3-Triazole-based analogue of benznidazole displays remarkable activity against Trypanosoma cruzi, Bioorg. Med. Chem. 23 (2015) 6815-6826, https://doi.org/10.1016/ j.bmc.2015.10.008

[38] C. Fonseca-Berzal, A. Ibáñez-Escribano, F. Reviriego, J. Cumella, P. Morales N. Jagerovic, J.J. Nogal-Ruiz, J.A. Escario, P.B. Da Silva, M.D.N.C. Soeiro, A. Gómez-Barrio, V.J. Arán, Antichagasic and trichomonacidal activity of 1substituted 2-benzyl-5-nitroindazolin-3-ones and 3-alkoxy-2-benzyl-5nitro-2H-indazoles, Eur. J. Med. Chem. 115 (2016) 295-310, https:// doi.org/10.1016/j.ejmech.2016.03.036.

[39] F.T. Silva, C.H. Franco, D.C. Favaro, L.H. Freitas-Junior, C.B. Moraes, E.I. Ferreira, Design, synthesis and antitrypanosomal activity of some nitrofurazone 1,2,4-triazolic bioisosteric analogues, Eur. J. Med. Chem. 121 (2016) 553-560, https://doi.org/10.1016/j.ejmech.2016.04.065.

[40] W. Devine, J.L. Woodring, U. Swaminathan, E. Amata, G. Patel, J. Erath, N.E. Roncal, P.J. Lee, S.E. Leed, A. Rodriguez, K. Mensa-Wilmot, R.J. Sciotti, M.P. Pollastri, Protozoan parasite growth inhibitors discovered by crossscreening yield potent scaffolds for lead discovery, J. Med. Chem. 58 (2015) 5522-5537, https://doi.org/10.1021/acs.jmedchem.5b00515.

[41] A.G. Tempone, D.D. Ferreira, M.L. Lima, T.A. Costa Silva, S.E.T. Borborema J.Q. Reimão, M.K. Galuppo, J.M. Guerra, A.J. Russell, G.M. Wynne, R.Y.L. Lai, M.M. Cadelis, B.R. Copp, Efficacy of a series of alpha-pyrone derivatives against Leishmania (L.) infantum and Trypanosoma cruzi, Eur. J. Med. Chem. 139 (2017) 947-960, https://doi.org/10.1016/j.ejmech.2017.08.055.

[42] A.M.A. Velásquez, A.I. Francisco, A.A.N. Kohatsu, F.A.D.J. Silva, D.F. Rodrigues, R.G.D.S. Teixeira, B.G. Chiari, M.G.J. De Almeida, V.L.B. Isaac, M.D. Vargas, R.M.B. Cicarelli, Synthesis and tripanocidal activity of ferrocenyl and benzyl diamines against Trypanosoma brucei and Trypanosoma cruzi, Bioorg. Med. Chem. Lett 24 (2014) 1707-1710, https://doi.org/10.1016/ j.bmcl.2014.02.046.

[43] M. Couto, C. Sánchez, B. Dávila, V. Machín, J. Varela, G Álvarez, M. Cabrera L. Celano, B. Aguirre-López, N. Cabrera, M.T. De Gómez-Puyou, A. GómezPuyou, R. Pérez-Montfort, H. Cerecetto, M. González, 3-H-[1,2]Dithiole as a new anti-trypanosoma cruzi chemotype: biological and mechanism of action studies, Molecules 20 (2015) 14595-14610, https://doi.org/10.3390/ molecules200814595.

[44] P.J. Myler, Searching the tritryp genomes for drug targets, Adv. Exp. Med Biol. 625 (2008) 133-140, https://doi.org/10.1007/978-0-387-77570-8-11.

[45] B.S. Hall, C. Bot, S.R. Wilkinson, Nifurtimox activation by trypanosomal type I nitroreductases generates cytotoxic nitrile metabolites, J. Biol. Chem. 286 
(2011) 13088-13095, https://doi.org/10.1074/jbc.M111.230847.

[46] H. Cerecetto, M. González, Antiparasitic prodrug nifurtimox: revisiting its activation mechanism, Future Microbiol. 6 (2011) 847-850.

[47] S.R. Wilkinson, M.C. Taylor, D. Horn, J.M. Kelly, I. Cheeseman, A mechanism for cross-resistance to nifurtimox and benznidazole in trypanosomes, Proc. Natl. Acad. Sci. Unit. States Am. 105 (2008) 5022-5027, https://doi.org 10.1073/pnas.0711014105

[48] M.V. Papadopoulou, B.B. Trunz, W.D. Bloomer, C. McKenzie, S.R. Wilkinson, C. Prasittichai, R. Brun, M. Kaiser, E. Torreele, Novel 3-nitro-1H-1,2,4triazole-based aliphatic and aromatic amines as anti-chagasic agents, J. Med. Chem. 54 (2011) 8214-8223, https://doi.org/10.1021/jm201215n.

[49] S.R. Wilkinson, C. Bot, J.M. Kelly, B.S. Hall, Trypanocidal activity of nitroaromatic prodrugs: current treatments and future perspectives, Curr. Top. Med. Chem. 11 (2011) 2072-2084.

[50] M.V. Papadopoulou, W.D. Bloomer, G.I. Lepesheva, H.S. Rosenzweig, M. Kaiser, B. Aguilera-Venegas, S.R. Wilkinson, E. Chatelain, J.R. Ioset, Novel 3-nitrotriazole-based amides and canabinols as bifuncional anti-Chagasic agents, J. Med. Chem. 58 (2015) 1307-1319, https://doi.org/10.1002/ nbm.3066.Non-invasive.

[51] M.V. Papadopoulou, W.D. Bloomer, H.S. Rosenzweig, I.P. O'Shea, S.R. Wilkinson, M. Kaiser, E. Chatelain, J.-R. Ioset, Discovery of potent nitrotriazole-based antitrypanosomal agents: in vitro and in vivo evaluation, Bioorg. Med. Chem. 23 (2015) 6467-6476, https://doi.org/10.1016/ j.bmc.2015.08.014.

[52] I. Palos, E.E. Lara-Ramirez, J.C. Lopez-Cedillo, C. Garcia-Perez, M. Kashif, V. Bocanegra-Garcia, B. Nogueda-Torres, G. Rivera, Repositioning FDA drugs as potential cruzain inhibitors from Trypanosoma cruzi: virtual screening, in vitro and in vivo studies, Molecules 22 (2017), https://doi.org/10.3390/ molecules22061015.

[53] P.S. Doyle, Y.M. Zhou, I. Hsieh, D.C. Greenbaum, J.H. McKerrow, J.C. Engel, The trypanosoma cruzi protease cruzain mediates immune evasion, PLoS Pathog. 7 (2011) 1-11, https://doi.org/10.1371/journal.ppat.1002139.

[54] V.G. Duschak, A.S. Couto, Cruzipain, the major cysteine protease of Trypanosoma cruzi: a sulfated glycoprotein antigen as relevant candidate for vaccine development and drug target. A review, Curr. Med. Chem. 16 (2009) 3174-3202, https://doi.org/10.2174/092986709788802971.

[55] S.F.P. Braga, L.C. Martins, E.B. da Silva, P.A. Sales Júnior, S.M.F. Murta, A.J. Romanha, W.T. Soh, H. Brandstetter, R.S. Ferreira, R.B. de Oliveira, Synthesis and biological evaluation of potential inhibitors of the cysteine proteases cruzain and rhodesain designed by molecular simplification, Bioorg. Med. Chem. 25 (2017) 1889-1900, https://doi.org/10.1016 j.bmc.2017.02.009.

[56] A. Guerra, P. Gonzalez-Naranjo, N.E. Campillo, J. Varela, M.L. Lavaggi, A. Merlino, H. Cerecetto, M. González, A. Gomez-Barrio, J.A. Escario, C. Fonseca-Berzal, G. Yaluf, J. Paniagua-Solis, J.A. Páez, Novel Imidazo[4,5 -c ] $[1,2,6]$ thiadiazine 2,2-dioxides as antiproliferative trypanosoma cruzi drugs: computational screening from neural network, synthesis and in vivo biological properties, Eur. J. Med. Chem. 136 (2017) 223-234, https://doi.org 10.1016/j.ejmech.2017.04.075.

[57] B. Chance, G. Williams, W. Holmes, J. Higgins, Respiratory enzymes in oxidative phosphorylation, J. Biol. Chem. 217 (1955) 409-428. http://www. jbc.org/.

[58] T.R. Figueira, M.H. Barros, A.A. Camargo, R.F. Castilho, J.C.B. Ferreira, A.J. Kowaltowski, F.E. Sluse, N.C. Souza-Pinto, A.E. Vercesi, Mitochondria as a source of reactive oxygen and nitrogen species: from molecular mechanisms to human health, Antioxid. Redox Signal 18 (2013) 2029-2074, https:// doi.org/10.1089/ars.2012.4729.

[59] W. Dröge, Free radicals in the physiological control of cell function, Physiol. Rev. 82 (2002) 47-95, https://doi.org/10.1152/physrev.00018.2001.

[60] A.J. Kowaltowski, N.C. de Souza-Pinto, R.F. Castilho, A.E. Vercesi, Mitochondria and reactive oxygen species, Free Radic. Biol. Med. 47 (2009) 333-343, https://doi.org/10.1016/j.freeradbiomed.2009.05.004.

[61] R.F.S. Menna-Barreto, S.L. De Castro, The double-edged sword in pathogenic trypanosomatids: the pivotal role of mitochondria in oxidative stress and bioenergetics, BioMed Res. Int. 2014 (2014), https://doi.org/10.1155/2014/ 614014.

[62] E.A. Britta, D.B. Scariot, H. Falzirolli, C.C. Da Silva, T. Ueda-Nakamura, B.P. Dias Filho, R. Borsali, C.V. Nakamura, 4-Nitrobenzaldehyde thiosemicarbazone: a new compound derived from S-(-)-limonene that induces mitochondrial alterations in epimastigotes and trypomastigotes of Trypanosoma cruzi,

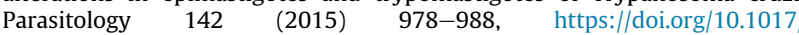
S0031182015000141.

[63] C.M.O. de Azeredo, E.P. Ávila, D.L.J. Pinheiro, G.W. Amarante, M.J. Soares Biological activity of the azlactone derivative EPA-35 against Trypanosoma cruzi, FEMS Microbiol. Lett. 364 (2017) 1-7, https://doi.org/10.1093/femsle/ fnx020.

[64] L.A. Cortes, L. Castro, B. Pesce, J.D. Maya, J. Ferreira, V. Castro-Castillo, E. Parra, J.A. Jara, R. López-Muñoz, Novel gallate triphenylphosphonium derivatives with potent antichagasic activity, PLoS One 10 (2015) 1-17, https://doi.org 10.1371/journal.pone.0136852.

[65] N.P. Nogueira, F.M.S. Saraiva, M.P. Oliveira, A.P.M. Mendonça, J.D.F. Inacio, E.E. Almeida-Amaral, R.F. Menna-Barreto, G.A.T. Laranja, E.J.L. Torres, M.F. Oliveira, M.C. Paes, Heme modulates Trypanosoma cruzi bioenergetics inducing mitochondrial ROS production, Free Radic. Biol. Med. 108 (2017) 183-191, https://doi.org/10.1016/j.freeradbiomed.2017.03.027.
[66] N.P. de Almeida Nogueira, C.F. de Souza, F.M. de Souza Saraiva, P.E. Sultano, S.R. Dalmau, R.E. Bruno, R. de Lima Sales Gonçalves, G.A.T. Laranja, L.H.M. Leal, M.G.P. Coelho, C.A. Masuda, M.F. Oliveira, M.C. Paes, HemeInduced ROS in Trypanosoma cruzi activates Camkii-Like that triggers epimastigote proliferation. One helpful effect of ROS, PLoS One 6 (2011), https:// doi.org/10.1371/journal.pone.0025935.

[67] A. Ganguly, K. Banerjee, P. Chakraborty, S. Das, A. Sarkar, A. Hazra, M. Banerjee, A. Maity, M. Chatterjee, N.B. Mondal, S.K. Choudhuri, Overcoming multidrug resistance (MDR) in cancer in vitro and in vivo by a quinoline derivative, Biomed. Pharmacother. 65 (2011) 387-394, https:// doi.org/10.1016/j.biopha.2011.04.024.

[68] T.S. Tiuman, A.O. Santos, T. Ueda-Nakamura, B.P.D. Filho, C.V. Nakamura, Recent advances in leishmaniasis treatment, Int. J. Infect. Dis. 15 (2011), https://doi.org/10.1016/j.ijid.2011.03.021.

[69] G.C. Muscia, S.I. Cazorla, F.M. Frank, G.L. Borosky, G.Y. Buldain, S.E. Asís, E.L. Malchiodi, Synthesis, trypanocidal activity and molecular modeling studies of 2-alkylaminomethylquinoline derivatives, Eur. J. Med. Chem. 46 (2011) 3696-3703, https://doi.org/10.1016/j.ejmech.2011.05.035.

[70] S. Eswaran, A.V. Adhikari, I.H. Chowdhury, N.K. Pal, K.D. Thomas, New quinoline derivatives: synthesis and investigation of antibacterial and antituberculosis properties, Eur. J. Med. Chem. 45 (2010) 3374-3383, https:// doi.org/10.1016/j.ejmech.2010.04.022.

[71] M. Foley, Quinoline Antimalarials mechanisms of action and resistance and prospects for new agents, Pharmacol. Ther. 79 (1998) 55-87, https://doi.org/ 10.1016/S0163-7258(98)00012-6.

[72] G.C. Lechuga, J.C. Borges, C.M. Calvet, H.P. de Araújo, A.A. Zuma, S.B. do Nascimento, M.C.M. Motta, A.M.R. Bernardino, M.C. de S. Pereira, S.C. Bourguignon, Interactions between 4-aminoquinoline and heme: promising mechanism against Trypanosoma cruzi, Int. J. Parasitol. Drugs Drug Resist 6 (2016) 154-164, https://doi.org/10.1016/j.ijpddr.2016.07.001.

[73] K. Temperton NJ, S.R. Wilkinson, J.M. Meyer DJ, Overexpressi on of superoxide dismutase in Trypanosoma cruzi results in increased sensitivity to the trypanocidal agents gentian violet and benznidazole, Mol. Biochem. Parasitol. 96 (1998) 167-176.

[74] L. Piacenza, G. Peluffo, M.N. Alvarez, A. Martínez, R. Radi, Trypanosoma cruzi antioxidant enzymes as virulence factors in chagas disease, Antioxid. Redox Signal 19 (2013) 723-734, https://doi.org/10.1089/ars.2012.4618.

[75] H. Mateo, C. Marin, G. Perez-Cordon, M. Sanchez-Moreno, Purification and biochemical characterization of four iron superoxide dismutases in Trypanosoma cruzi, Mem. Inst. Oswaldo Cruz 103 (2008) 271-276. S007402762008000300008 [pii].

[76] E. Moreno-Viguri, C. Jiménez-Montes, R. Martín-Escolano, M. SantivañezVeliz, A. Martin-Montes, A. Azqueta, M. Jimenez-Lopez, S. Zamora Ledesma, N. Cirauqui, A. López De Ceráin, C. Marín, M. Sánchez-Moreno, S. Pérez-Silanes, In vitro and in vivo anti-trypanosoma cruzi activity of new arylamine mannich Base-type derivatives, J. Med. Chem. 59 (2016) 10929-10945, https://doi.org/10.1021/acs.jmedchem.6b00784.

[77] M.O.F. Khan, Trypanothione reductase: a viable chemotherapeutic target for antitrypanosomal and antileishmanial drug design, Drug Target Insights 2 (2007) 129-146, https://doi.org/10.1055/s-2008-1032037.

[78] S. Krieger, W. Schwarz, L. Krauth-siegel, C.E. Clayton, Trypanosomes lacking trypanothione reductase are avirulent and show increased sensitivity to trivalent arsenicals and oxidative stress, Mol. Microbiol. 35 (2000) 542-55227.

[79] M. Beig, F. Oellien, L. Garoff, S. Noack, R. Luise Krauth-Siegel, P.M. Selzer, Trypanothione reductase: a target protein for a combined in vitro and in silico screening approach, PLoS Neglected Trop. Dis. 9 (2015) 1-19, https:// doi.org/10.1371/journal.pntd.0003773.

[80] C.S. Bond, Y. Zhang, M. Berriman, M.L. Cunningham, A.H. Fairlamb, W.N. Hunter, Crystal structure of Trypanosoma cruzi trypanothione reductase in complex with trypanothione, and the structure-based discovery of new natural product inhibitors, Structure 7 (1999) 81-89, https://doi.org/ 10.1016/S0969-2126(99)80011-2.

[81] A.H. Fairlamb, P. Blackburn, P. Ulrich, B.T. Chait, A. Cerami, Trypanothione: a novel bis(glutathionyl)spermidine cofactor for glutathione reductase in trypanosomatids, Science 227 (1985) 1485-1487, https://doi.org/10.1126/ science.3883489.

[82] R. da Rosa, M.H. de Moraes, L.A. Zimmermann, E.P. Schenkel, M. Steindel, L.S.C. Bernardes, Design and synthesis of a new series of 3,5-disubstituted isoxazoles active against Trypanosoma cruzi and Leishmania amazonensis, Eur. J. Med. Chem. 128 (2017) 25-35, https://doi.org/10.1016/ j.ejmech.2017.01.029.

[83] J.A. Urbina, J.L. Concepcion, S. Rangel, G. Visbal, R. Lira, Squalene synthase as a chemotherapeutic target in Trypanosoma cruzi and Leishmania mexicana, Mol. Biochem. Parasitol. 125 (2002) 35-45, https://doi.org/10.1016/S01666851(02)00206-2.

[84] N. Shang, Q. Li, T.P. Ko, H.C. Chan, J. Li, Y. Zheng, C.H. Huang, F. Ren, C.C. Chen, Z. Zhu, M. Galizzi, Z.H. Li, C.A. Rodrigues-Poveda, D. Gonzalez-Pacanowska, P. Veiga-Santos, T.M.U. de Carvalho, W. de Souza, J.A. Urbina, A.H.J. Wang, R. Docampo, K. Li, Y.L. Liu, E. Oldfield, R.T. Guo, Squalene synthase as a target for chagas disease therapeutics, PLoS Pathog. 10 (2014), https://doi.org/ 10.1371 /journal.ppat.1004114.

[85] G.M. Cinque, Structure-activity relationship of new growth inhibitors of trypanosoma cruzi, J. Med. Chemestry 41 (1998) 1540-1554.

[86] M.N. Chao, M. Storey, C. Li, M.G. Rodríguez, F. Di Salvo, S.H. Szajnman, 
S.N.J. Moreno, R. Docampo, J.B. Rodriguez, Selenium-containing analogues of WC-9 are extremely potent inhibitors of Trypanosoma cruzi proliferation, Bioorg. Med. Chem. 25 (2017) 6435-6449, https://doi.org/10.1016/ j.bmc.2017.10.016.

[87] M. Ferrer-Casal, C. Li, M. Galizzi, C.A. Stortz, S.H. Szajnman, R. Docampo, S.N.J. Moreno, J.B. Rodriguez, New insights into molecular recognition of 1,1bisphosphonic acids by farnesyl diphosphate synthase, Bioorg. Med. Chem. 22 (2014) 398-405, https://doi.org/10.1016/j.neuron.2009.10.017.A.

[88] B. Demoro, F. Caruso, M. Rossi, D. Benítez, M. González, H. Cerecetto, M. Galizzi, L. Malayil, R. Docampo, R. Faccio, Á.W. Mombrú, D. Gambino, L. Otero, Bisphosphonate metal complexes as selective inhibitors of Trypanosoma cruzi farnesyl diphosphate synthase, Dalton Trans. 41 (2012) 6468-6476, https://doi.org/10.1039/c2dt12247b.

[89] S.B. Gabelli, J.S. McLellan, A. Montalvetti, E. Oldfield, R. Docampo, L.M. Amzel, Structure and mechanism of the farnesyl diphosphate synthase from Trypanosoma cruzi: implications for drug design, Proteins Struct. Funct. Bioinforma 62 (2006) 80-88, https://doi.org/10.1002/prot.20754.

[90] S. Aripirala, S.H. Szajnman, J. Jakoncic, J.B. Rodriguez, R. Docampo, S.B. Gabelli, L.M. Amzel, Design, synthesis, calorimetry and crystallographic analysis of 2-alkylaminoethyl-1,1-bisphosphonates as inhibitors of Trypanosoma cruzi farnesyl diphosphate synthase, J. Med. Chem. 55 (2012) 6445-6454, https://doi.org/10.1158/1940-6207.CAPR-14-0359.Nrf2dependent.

[91] J.A. Urbina, B. Moreno, S. Vierkotter, E. Oldfield, G. Payares, C. Sanoja, B.N. Bailey, W. Yan, D.A. Scott, S.N.J. Moreno, R. Docampo, Trypanosoma cruzi contains major pyrophosphate stores, and its growth in vitro and in vivo is blocked by pyrophosphate analogs, J. Biol. Chem. 274 (1999) 33609-33615, https://doi.org/10.1074/jbc.274.47.33609.

[92] S.H. Szajnman, G.E. García Liñares, Z.-H. Li, C. Jiang, M. Galizzi, E.J. Bontempi, M. Ferella, S.N.J. Moreno, R. Docampo, J.B. Rodriguez, Synthesis and biological evaluation of 2-alkylaminoethyl-1,1-bisphosphonic acids against Trypanosoma cruzi and Toxoplasma gondii targeting farnesyl diphosphate synthase, Bioorg. Med. Chem. 16 (2008) 3283-3290, https://doi.org/10.1016/ j.bmc.2007.12.010.

[93] M. Recher, A.P. Barboza, Z.H. Li, M. Galizzi, M. Ferrer-Casal, S.H. Szajnman, R. Docampo, S.N.J. Moreno, J.B. Rodriguez, Design, synthesis and biological evaluation of sulfur-containing 1,1-bisphosphonic acids as antiparasitic agents, Eur. J. Med. Chem. 60 (2013) 431-440, https://doi.org/10.1016/ j.ejmech.2012.12.015.

[94] P.D. Leeson, B. Springthorpe, The influence of drug-like concepts on decisionmaking in medicinal chemistry, Nat. Rev. Drug Discov. 6 (2007) 881-902, https://doi.org/10.1038/nrd2445.

[95] W. Curatolo, Physical chemical properties of oral drug candidates in the discovery and exploratory development settings, Pharmaceut. Sci. Technol. Today 1 (1998) 387-393, https://doi.org/10.1016/S1461-5347(98)00097-2.

[96] M.C. Wenlock, P. Barton, In silico physicochemical parameter predictions, Mol. Pharm. 10 (2013) 1224-1235, https://doi.org/10.1021/mp300537k.

[97] I.V. Tetko, Computing chemistry on the web, Drug Discov. Today 10 (2005) 1497-1500, https://doi.org/10.1016/S1359-6446(05)03584-1.

[98] C.A. Lipinski, F. Lombardo, B.W. Dominy, P.J. Feeney, Experimental and computational approaches to estimate solubility and permeability in drug discovery and developmental settings, Adv. Drug Deliv. Rev. 23 (1997) 3-25, https://doi.org/10.1016/S0169-409X(96)00423-1.

[99] C.A. Lipinski, F. Lombardo, B.W. Dominy, P.J. Feeney, Experimental and computational approaches to estimate solubility and permeability in drug discovery and development settings, Adv. Drug Deliv. Rev. 46 (2001) 3-26.

[100] E.S. Zuniga, J. Early, T. Parish, The future for early-stage tuberculosis drug discovery, Future Microbiol. 10 (2015) 217-229, https://doi.org/10.2217/ fmb.14.125.

[101] U.H. Manjunatha, P.W. Smith, Perspective: challenges and opportunities in TB drug discovery from phenotypic screening, Bioorg. Med. Chem. 23 (2015) 5087-5097, https://doi.org/10.1016/j.bmc.2014.12.031.

[102] M.J. Waring, Lipophilicity in drug discovery, Expet Opin. Drug Discov. 5 (2010) 235-248, https://doi.org/10.1517/17460441003605098.

[103] M. Chen, J. Borlak, W. Tong, High lipophilicity and high daily dose of oral medications are associated with significant risk for drug-induced liver injury, Hepatology 58 (2013) 388-396.

[104] A. Tarcsay, G.M. Keserü, Contributions of molecular properties to drug promiscuity, J. Med. Chem. 56 (2013) 1789-1795, https://doi.org/10.1021/ jm301514n.

[105] Y. Li, U. Theuretzbacher, C.J. Clancy, M.H. Nguyen, H. Derendorf, Pharmacokinetic/Pharmacodynamic profile of posaconazole, Clin. Pharmacokinet. 49 (2010) 379-396.

[106] M.J. Pinazo, G. Espinosa, M. Gallego, P.L. Lopez-Chejade, J.A. Urbina, J. Gascon, Successful treatment with posaconazole of a patient with chronic chagas disease and systemic lupus erythematosus, Am. J. Trop. Med. Hyg. 82 (2010) 583-587, https://doi.org/10.4269/ajtmh.2010.09-0620.

[107] G.I. Lepesheva, T.Y. Hargrove, S. Anderson, Y. Kleshchenko, V. Furtak, Z. Wawrzak, F. Villalta, M.R. Waterman, Structural insights into inhibition of sterol 14??-demethylase in the human pathogen Trypanosoma cruzi, J. Biol. Chem. 285 (2010) 25582-25590, https://doi.org/10.1074/jbc.M110.133215.

[108] J.a Urbina, G. Payares, L.M. Contreras, C. Sanoja, J. Molina, M. Piras, N. Perez, P. Wincker, D. Loebenberg, Antiproliferative effects and mechanism of action of SCH 56592 against trypanosoma ( schizotrypanum ) cruzi : in vitro and in vivo studies antiproliferative effects and mechanism of action of $\mathrm{SCH}$
56592 against trypanosoma ( schizotrypanum ) cruzi, In Vitis 42 (1998) $1771-1777$.

[109] J. Molina, O. Martins-Filho, Z. Brener, A.J. Romanha, D. Loebenberg J.A. Urbina, Activities of the triazole derivative SCH 56592 (Posaconazole) against drug-resistant strains of the protozoan parasite Trypanosoma (Schizotrypanum) cruzi in immunocompetent and immunosuppressed murine hosts, Antimicrob. Agents Chemother. 44 (2000) 150-155, https:// doi.org/10.1128/AAC.44.1.150-155.2000.

[110] L. de F. Diniz, J.A. Urbina, I.M. de Andrade, A.L. Mazzeti, T.A.F. Martins, I.S. Caldas, A. Talvani, I. Ribeiro, M.T. Bahia, Benznidazole and posaconazole in experimental chagas disease: positive interaction in Concomitant and sequential treatments, PLoS Neglected Trop. Dis. 7 (2013), https://doi.org/ 10.1371 /journal.pntd.0002367.

[111] ClinicalTrials.gov., A study of the use of oral posaconazole (POS) in the treatment of asymptomatic chronic Chagas disease (P05267)(STOP CHAGAS), (n.d.). http://clinicaltrials.gov/show/NCT0 1377480 (accessed November 22, 2017).

[112] A.F. Francisco, M.D. Lewis, S. Jayawardhana, M.C. Taylor, E. Chatelain, J.M. Kelly, Limited ability of posaconazole to cure both acute and chronic Trypanosoma cruzi infections revealed by highly sensitive in vivo imaging, Antimicrob. Agents Chemother. 59 (2015) 4653-4661, https://doi.org/ 10.1128/AAC.00520-15.

[113] J.A. Urbina, G. Payares, C. Sanoja, R. Lira, A.J. Romanha, In vitro and in vivo activities of ravuconazole on Trypanosoma cruzi, the causative agent of Chagas disease, Int. J. Antimicrob. Agents 21 (2003) 27-38 doi: S092485790200273X [pii].

[114] H. Yamaguchi, Potential of ravuconazole and its prodrugs as the new oral therapeutics for onychomycosis, Med. Mycol. J. 57 (2016) E93-E110. http:// www.embase.com/search/results? subaction=viewrecord\%7B\%25\%7D7B\% 7B\&\%7D\%7B\%25\%7D7Dfrom=export\%7B\%25\%7D7B\%7B\&\%7D\%7B\%25\% 7D7Did=L613806785.

[115] ClinicalTrialsgov, Pivotal study of fexinidazole for human African trypanosomiasis in stage 2. https://clinicaltrials.gov/ct2/show/NCT01685827, 2012. (Accessed 29 December 2017).

[116] L.D.F. Diniz, I.S. Caldas, P.M.D.M. Guedes, G. Crepalde, M. De Lana C.M. Carneiro, A. Talvani, J.A. Urbina, M.T. Bahia, Effects of ravuconazole treatment on parasite load and immune response in dogs experimentally infected with Trypanosoma cruzi, Antimicrob. Agents Chemother. 54 (2010) 2979-2986, https://doi.org/10.1128/AAC.01742-09.

[117] J.C. Engel, P.S. Doyle, I. Hsieh, J.H. McKerrow, Cysteine protease inhibitors cure an experimental Trypanosoma cruzi infection, J. Exp. Med. 188 (1998) 725-734, https://doi.org/10.1084/jem.188.4.725.

[118] P.S. Doyle, Y.M. Zhou, J.C. Engel, J.H. McKerrow, A cysteine protease inhibitor cures Chagas' disease in an immunodeficient-mouse model of infection, Antimicrob, Agents Chemother 51 (2007) 3932-3939, https://doi.org/ 10.1128/AAC.00436-07.

[119] S.C. Barr, K.L. Warner, B.G. Kornreic, J. Piscitelli, A. Wolfe, L. Benet, J.H. Mckerrow, A cysteine protease inhibitor protects dogs from cardiac damage during infection by Trypanosoma cruzi A Cysteine protease inhibitor protects dogs from cardiac damage during infection by trypanosoma cruzi, Antimicrob. Agents Chemother 49 (2005) 5160-5162, https://doi.org/ 10.1128/AAC.49.12.5160.

[120] M. Ndao, C. Beaulieu, W.C. Black, E. Isabel, F. Vasquez-Camargo, M. NathChowdhury, F. Massé, C. Mellon, N. Methot, D.A. Nicoll-Griffith, Reversible cysteine protease inhibitors show promise for a chagas disease cure, Antimicrob. Agents Chemother. 58 (2014) 1167-1178, https://doi.org/10.1128/ AAC.01855-13.

[121] C. Davies, R.M. Cardozo, O.S. Negrette, M.C. Mora, M.C. Chung, M.Á. Basombrío, Hydroxymethylnitrofurazone is active in a murine model of Chagas' disease, Antimicrob. Agents Chemother. 54 (2010) 3584-3589, https://doi.org/10.1128/AAC.01451-09.

[122] M.C. Chung, R.V. Carvalho Güido, T. Favarato Martinelli, M. Ferreira Gonçalves, M. Carneiro Polli, K.C. Alves Botelho, E. Aparecida Varanda, W. Colli, M.T.M. Miranda, E. Igne Ferreira, Synthesis and in vitro evaluation of potential antichagasic hydroxymethylnitrofurazone (NFOH-121): a new nitrofurazone prodrug, Bioorg. Med. Chem. 11 (2003) 4779-4783, https://doi.org/ 10.1016/j.bmc.2003.07.004

[123] M.C. Guido, R.V.C. Ferreira, E.I. Nassute, J.C. Varanda, E.A. Chung, Diminuição da atividade mutagênica do pró-fármaco NFOH-121 em relação ao nitrofural (nitrofurazona), Rev. Cienc. Farm. 22 (2001) 319-333.

[124] G.H.G. Trossini, A. Malvezzi, A. T-do Amaral, C.O. Rangel-Yagui, M. a Izidoro, M.H.S. Cezari, L. Juliano, M.C. Chung, C.M.S. Menezes, E.I. Ferreira, Cruzain inhibition by hydroxymethylnitrofurazone and nitrofurazone: investigation of a new target in Trypanosoma cruzi, J. Enzym. Inhib. Med. Chem. 25 (2010) 62-67, https://doi.org/10.3109/14756360902941058.

[125] C. Davies, N. Dey, O.S. Negrette, L.A. Parada, M.A. Basombrio, N.J. Garg, Hepatotoxicity in mice of a novel anti-parasite drug candidate hydroxymethylnitrofurazone: a Comparison with benznidazole, PLoS Neglected Trop. Dis. 8 (2014), https://doi.org/10.1371/journal.pntd.0003231.

[126] S. Ekins, J.L. de Siqueira-Neto, L.-I. McCall, M. Sarker, M. Yadav, E.L. Ponder E.A. Kallel, D. Kellar, S. Chen, M. Arkin, B.A. Bunin, J.H. McKerrow, C. Talcott, Machine learning models and pathway genome data base for trypanosoma cruzi drug discovery, PLoS Neglected Trop. Dis. 9 (2015), https://doi.org/ $10.1371 /$ journal.pntd.0003878 e0003878. 